\title{
Review Article \\ Skin Cancer and Its Treatment: Novel Treatment Approaches with Emphasis on Nanotechnology
}

\author{
Kristjan Orthaber, ${ }^{1}$ Matevž Pristovnik, ${ }^{1}$ Kristijan Skok, ${ }^{1}$ Barbara Perić, ${ }^{2}$ and Uroš Maver \\ ${ }^{1}$ Faculty of Medicine, Institute of Biomedical Sciences, University of Maribor, Taborska Ulica 8, SI-2000 Maribor, Slovenia \\ ${ }^{2}$ Institute of Oncology Ljubljana, Zaloška 2, SI-1000 Ljubljana, Slovenia \\ Correspondence should be addressed to Uroš Maver; uros.maver@um.si
}

Received 13 October 2016; Accepted 23 January 2017; Published 19 February 2017

Academic Editor: William Yu

Copyright (c) 2017 Kristjan Orthaber et al. This is an open access article distributed under the Creative Commons Attribution License, which permits unrestricted use, distribution, and reproduction in any medium, provided the original work is properly cited.

\begin{abstract}
The life expectancy in the Western world is increasing for a long time, which is the courtesy of a higher life standard, a more thorough hygiene, and, of course, the progress of modern medicine. Nevertheless, one of the illnesses that still proves to be a great challenge regardless of the recent advancements in medicine is cancer. Skin cancer is, according to the World Health Organization, the most common malignancy for the white population. The beginning of the paper offers a brief overview of the latest available information concerning epidemiology, aetiology, diagnostics, and treatment options for skin cancer, whereas the rest of the article deals with modern approaches to skin cancer treatment, highlighting recent development of nanotechnology based treatment approaches. Among these, we focus especially on the newest nanotechnological approaches combined with chemotherapy, a field which specialises in target specificity, drug release control, and real time monitoring with the goal being to diminish unwanted side effects and their severity, achieving a cheaper treatment and a generally more efficient chemotherapy. The field of nanotechnology is a rapidly developing one, judging by already approved clinical studies or by new theranostic agents that combine both the therapeutic and diagnostic modalities.
\end{abstract}

\section{Introduction}

Despite the past two decades' advancements, cancer treatment remains a challenge and a motivation for many researchers worldwide. New treatment possibilities are constantly arising and show promise in improving treatment effectiveness, survival rates, and the patient quality of life, while at the same time decreasing unwanted side effects.

This article is an overview of various types of skin cancer, their characteristics, prevalence, and currently used treatment methods, including modern nanotechnology based methods. The latter are constantly improving our treatment possibilities by taking advantage of the specific properties of nanoparticles as carriers and more efficient targeting of the specific properties of cancer cells. We conclude with several prospects of the future in skin cancer treatment.

\section{About Skin Cancer}

Skin cancer is the most common malignant disease found particularly in Caucasians [1]. More than a million new cases are reported worldwide each year. The various types of skin cancer are named after the cells they originate from and their clinical behaviour. The most common types are basal cell carcinoma (BCC), squamous cell carcinoma (SCC) (together referred to as nonmelanocytic skin cancers (NMSC)), and malignant melanoma (MM) [2].

2.1. Nonmelanocytic Skin Cancer. NMSC is the most common malignancy found in humans. Each year 2-3 million new cases are reported worldwide, 1,3 million of those are found in the USA only [3]. In Europe, Canada, the USA, and Australia the incidence is increasing by $3-8 \%$ per year [4]. The incidence rate is thought to double in the next 30 years [5]. The most important etiological factors include UV light, ionizing radiation, and certain chemical carcinogens. A more detailed overview is shown in Table 1.

BCC represents $80-85 \%$ of all NMSC, which makes it the most common skin cancer type. In the USA, 30\% of all newly diagnosed cancers are BCC [4]. Worldwide, the incidence 


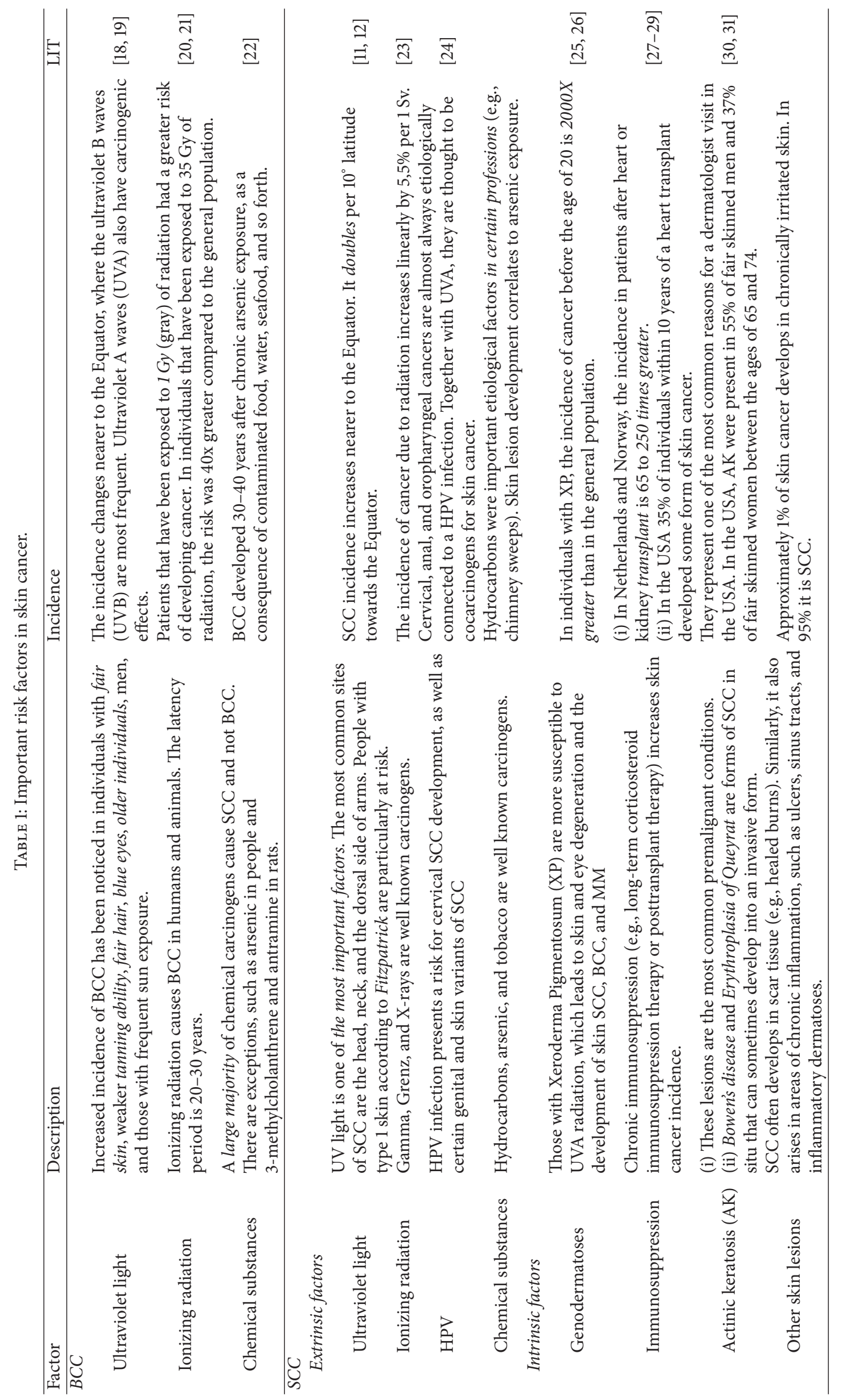




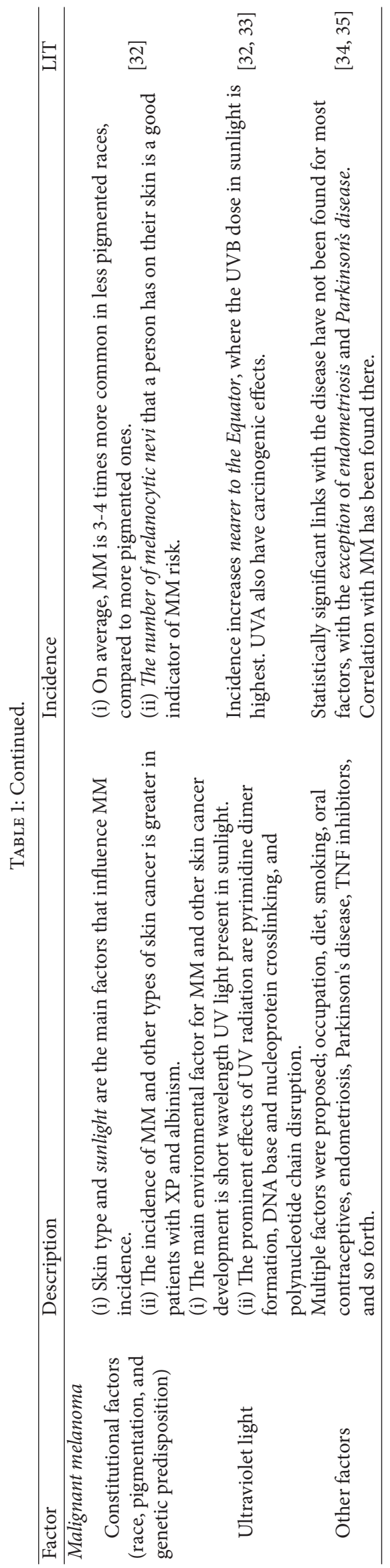




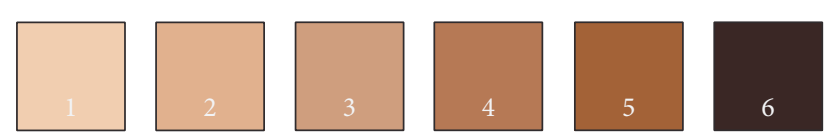

Figure 1: Skin types according to Fitzpatrick and Sober [12]. Sun exposed skin: type 1 always reddens and rarely tans; type 2 often reddens and rarely tans; type 3 mildly reddens and gradually tans; type 4 rarely reddens and easily tans; type 5 rarely reddens and easily tans; type 6 never reddens.

increases by $10 \%$ per year, mostly in older men, but also in young women $[2,6]$.

People who get skin cancer show typical signs of chronic sun damage, for example, collagenosis, irregular pigmentation, wrinkling of the skin, telangiectasia of the skin, and solar keratosis on sun exposed areas. Superficial BCC is of a red, slightly wrinkled, and scaled appearance with small ulcerations on the most exposed areas. They can be round or oval shaped with a poor defined border. The centre can be uniformly fibrotic. A superficial BCC can clinically appear as subacute or chronic dermatitis [7].

The other type of NMSC is SCC, which represents $15-20 \%$ of all NMSC, whose growth exhibits local destructiveness and surrounding tissue invasion, and also causes death more frequently than BCC [4]. Its incidence is increasing, though the increasing rate varies geographically [8]. The risk factors that lead to SCC development can be divided into extrinsic (UVA, ionizing radiation, human papilloma virus (HPV), and chemical substances) and intrinsic (genodermatoses, immunosuppression, preexisting skin lesion, and preexisting actinic keratosis). Further details can be found in Table 1.

2.2. Malignant Melanoma. Skin melanocytes are cells that produce the skin pigment melanin, and MM affects them specifically. Its incidence is still on the rise in areas with light skinned population that is overly exposed to sun radiation. Only Australia, with an incidence of 50-60/100000, reports a slowly declining trend since 2005 [9]. In Europe the incidence of this kind of skin cancer is 10-20/100000 inhabitants, while the USA stands at 20-30/100000. Slovenian incidence has, in the year 2012, been $23,1 / 100000$ in the male population and $23,8 / 100000$ in the female population. Thus, the yearly incidence of new diagnoses for Slovenia alone is about 700 new patients [10].

Even with MM representing a mere $4 \%$ of newly discovered cancers, it takes the sixth place as the most common female and seventh as the most common male cancer in Slovenia. In the rest of the world, the MM is more common in males than in females.

According to a 2010 research, 13200 [4] new cases of MM are found annually, whereby the incidence in the Caucasian population is sixteen times greater than in Afro-Americans and ten times greater than in Latin-Americans [4]. The most prominent etiological factors are constitutional factors, UV light, and other factors [11] (Table 1).

$\mathrm{MM}$ is most often developed in skin melanocytes, which are intermittently exposed to the sun radiation. Development from the retinal, anogenital, and the gastrointestinal tract is rarer. There are multiple MM risk factors.

Skin Type. The risk depends on the skin type. The highest is in people with light skin ( 1 in 40 ), while it is considerably lower in dark skinned people (1 in 1000) or Latin-Americans (1 in 200). The type of developed MM also depends on skin type, with dark skinned individuals; the acral lentiginous type, which usually presents itself on hands or soles of the feet, is the most common. In Caucasians, there are six distinguished skin types, and the highest risk is in individuals of skin types I and II. A depiction of said types can be seen in Figure 1.

Sun Radiation. MM and NMSC risk depends on both skin type and UV exposal. Both UVA and UVB of natural or artificial origin are cancerogenic. While the UV rays induce the desired tanning and vitamin $\mathrm{D}$ production, they also have a mutagenic effect and depress the immune system. [2]. The most important risk factor is the so-called intermittent sun exposure, as well as the childhood and adolescence sun exposure. The weaker risk factor is a chronic or professional exposure, except in head and neck MM. Other risk factors are also connected to the UV exposure; the number of newly formed naevi (see below for further details), sunburns, and presence of actinic keratosis are statistically linked to a higher risk for this type of cancer.

Naevi. Along with the skin type and UV exposure, the number of atypical (dysplastic) naevi also contributes to an increased risk. Characterized as such are naevi bigger than $6 \mathrm{~mm}$ in diameter, with uneven shape and colour. If we count more than 50 atypical naevi in a single individual, the state is called atypical naevi syndrome. This state increases MM risk fivefold. Even in people with multiple atypical naevi, MM most commonly develops in formerly unaltered skin; therefore the removal of unsuspicious dysplastic naevi is not advisable [2].

Age. MM incidence increases with age, while the average patient age is 62 years. It has to be pointed out nevertheless that MM is still one of the most common cancers in young adults as well [10].

Gender. In most countries, the male population is more susceptible for MM than the female. Life risk for men is 1,5 times higher than that of women. Slovenian incidence of MM is higher in women than in men [10].

Immunosuppression. Immunosuppression is a MM risk factor, which also decreases the patient survival [13].

Formerly Removed MM. In patients with MM, the risk for new $\mathrm{MM}$ is 3-7\% [13].

Family History. 5-10\% of MM appears in the "high-risk" families. Two or more close relatives with MM mean increased 
risk. Alongside MM, these families are also more susceptible for pancreatic cancer, mesothelioma, and retinal melanoma. Familial form of MM is connected to low and high penetrance genes. The most commonly known low penetrance gene is MC1R. Thus far, the high penetrance genes are CDK4, CDKN2A, POT1, TERT, and BAP1. The CDKN2A mutation is discovered in $2 \%$ of the $\mathrm{MM}$ patients, making it most commonly connected to the disease.

MM has to be always on our differential diagnosis list when a pigmented skin lesion or a long-standing stable nevus starts to change colour, shape, or size. Seen can be a change of colour, bigger radius, uneven borders, and sometimes bleeding, itching, and pain in the lesion [14]. These criteria are nicely presented in the mnemonic ABCDE (asymmetry, border, colour, dimension, and evolution).

2.3. Skin Cancer Diagnostics. Skin cancer diagnosis begins with a dermatological examination, medical history, dermoscopy, and surgical biopsy with pathohistological biopsy. Dermoscopy is a noninvasive method, where we use a lens (a lens system) and a strong light source, which enables us to distinguish typical skin cancer skin changes. With both MM and NMSC, one confirms the diagnosis of a suspect lesion with skin biopsy and a pathohistological examination. The biopsy includes an excision of $2-5 \mathrm{~mm}$ of healthy skin and is performed either using punch or shave biopsy. Further therapy is decided based on the anatomical site and size of the tumour.

\section{Current Therapeutic Approaches in Treating Skin Cancer}

\subsection{Surgery}

NMSC. There are many treatment options for the NMSC. The most appropriate is surgery through a radical excision. If the tumour of less than $2 \mathrm{~mm}$ in diameter is excised with a border of $4 \mathrm{~mm}$ of healthy skin, the recurrence is present in only $5 \%$ of cases $[15,16]$. For superficial tumours, a $2-3 \mathrm{~mm}$ border is sufficient [17]. The excision must be as deep as the hypodermis.

Whenever a radical excision is not an option due to an unfavourable cosmetic defect or accompanying disease, one of the following treatment options may be used. Cryotherapy, curettage and electrodessication, radiotherapy, topical application of 5-fluorouracil or imiquimod, electrodessication with curettage, and diathermia are the appropriate treatment options for superficial BCC and Bowen's disease of the thorax and limbs. Of course, in such cases the patient should always be warned of a higher recurrence risk. Radical excision is the treatment of choice in case of a recurrence [16].

MM. Local treatment of MM consists of a radical excision of the skin tumour or the biopsy site. It consists of a healthy skin border as well as the tumour. The area of the border depends on the thickness of the tumour and extends to the deep fascia. The recommended radical excision border widths are shown in Table 2. Such skin defects are usually primarily sutured, but if this is impossible, a skin graft is used [17].
TABLE 2: Breslow's depth.

\begin{tabular}{lc}
\hline Breslow tumour thickness & Recommended excision margin \\
\hline$<1 \mathrm{~mm}$ & $1 \mathrm{~cm}$ \\
$1-2 \mathrm{~mm}$ & $1-2 \mathrm{~cm}$ \\
$2-4 \mathrm{~mm}$ & $2 \mathrm{~cm}$ \\
$>4 \mathrm{~mm}$ & $2 \mathrm{~cm}$ \\
\hline
\end{tabular}

The tumour is classified using the Breslow classification, which depends on the tumour depth and sorts the tumour into one of the five stages. Stage I means that the tumour cells have infiltrated up to $0,75 \mathrm{~mm}$, stage II $0,76-1,5 \mathrm{~mm}$, stage III 1,51-2,25 mm, stage IV 2,26-3,0 $\mathrm{mm}$, and stage $\mathrm{V}$ deeper than 3,0 $\mathrm{mm}[36]$.

Metastases are discovered in about $20 \%$ of all MM patients. Based on the histopathological examination, clinicians decide on the possible sentinel node biopsy in the MM patients. This procedure is used for discovering of metastases that are clinically (palpation, ultrasound, and cytological puncture) invisible, due to an insufficient tumour mass. The removed sentinel node is inspected by a pathologist. Further MM treatment depends on the test results [37].

Clinically apparent regional lymph node metastases, discovered by palpation or ultrasound, are confirmed by a thin needle aspiration biopsy, followed by a cytological analysis of the gathered material. In case of a positive result (a metastatic node), a therapeutical dissection is immediately performed. Therapeutical dissection is a radical metastatic node removal in the individual nodal regions.

\section{2. "Basic" Pharmacological Therapy}

NMSC. Although the golden standard for NMSC is a surgical excision, the treatment of choice for the Bowen's disease is a local, topically applied 5-fluorouracil. Imiquimod and 5fluorouracil can also be used for the treatment of superficial BCC (except for the nodular form). Morbidity and mortality have been significantly decreased by newer drugs that regulate some key cell receptors (i.e., 5-fluorouracil) and the immune response. Imiquimod (which does not affect the mortality) and interferons (i.e., IFN- $\alpha 2 b$ ) are some of these. For systemic therapy, especially for MM, dacarbazine, temozolomide, or carboplatin/paclitaxel are also used [2].

Vismodegib is the first oral selective inhibitor of the Hedgehog signal pathway (HPI, Hedgehog Pathway Inhibitor). It binds selectively to the transmembrane smoothened protein (encoded by the SMO gene), where it inhibits the hedgehog signalling pathway, which also inhibits tumour growth. Two clinical studies were performed, namely, ERIVANCE BCC and STEVIE, where vismodegib was used in patients with advanced or metastatic BCC, some of which were also Gorlin syndrome patients [38].

$M M$. There have been no novel approaches in systemic metastatic MM treatment. Dimethyl triazeno imidazole carboxamide (DTIC, analogue temozolomide) is the only recommended monotherapy, though it was only effective in rare patients. In case of a lack of response to the DTIC 
therapy, a cisplatin (or its analogues) combined with other cytostatic drugs (carboplatin, nitrourea, taxanes, vindesine, and vinblastine) may be effective. Unfortunately, this comes at a cost of more unwanted side effects, while the prognosis remains unchanged [2].

\subsection{Targeted Therapy}

3.3.1. BRAF and MEK. The discovery that up to $66 \%$ of $M M$ harbour activating mutations in serine/threonine-protein kinase (BRAF), which results in a constitutively active kinase leading to unregulated growth and proliferation, has led to the development of different targeted therapies, as well as affecting the general diagnostic approach in patients with metastatic diseases. Hence, the testing for BRAF mutations should therefore be considered in all patients with metastatic disease, either by polymerase chain reaction (PCR) or immunohistochemistry (IHC) [39].

Highly selective BRAFV600 inhibitors such as vemurafenib and dabrafenib represented a breakthrough in the treatment of metastatic melanoma. Vemurafenib showed and improved response rate and median overall survival when compared to dacarbazine. Dabrafenib improved progressfree survival and median survival in stage IV MM patients, compared to those treated with dacarbazine [39].

The major issue in most patients is the development of resistance, whereas the mitogen-activated protein kinase (MAPK) pathway reactivation appears to play a major role [39]. Mitogen-activated protein kinase (MEK) is a serine/tyrosine/threonine kinase, which is an important part of the MAPK pathway. One key strategy has been the simultaneous inhibition of both BRAF and MAPK pathways, which is based on data from preclinical studies that have shown that dual BRAF and MEK inhibition increases apoptosis and delays the onset of resistance compared to BRAF inhibitors alone [39]. Furthermore, a common mechanism of resistance to BRAF inhibitors is reactivation of the MAPK pathway. For this reason, it was hypothesized that BRAF inhibitors combined with MEK inhibitors would potentially overcome such resistance. It has been shown that the combination has improved response rates, led to improvements in progression-free survival, and increased the overall survival with manageable toxicity [39].

Previous attempts at targeting mitogen-activated protein kinase kinase (MEK) were limited by toxicity and limited antitumor ability. Newer MEK inhibitors (selumetinib, trametinib, cobimetinib, and binimetinib) have shown promise and have been developed along with BRAF inhibitors as a part of a combination therapeutic strategy [39].

As monotherapy, trametinib showed a survival advantage compared with conventional chemotherapy. Binimetinib has shown similar clinical efficacy in BRAF-mutant melanoma and activity in NRAS-mutant melanoma. Selumetinib has shown an improvement in progress-free survival when compared to chemotherapy. However, the overall response rates are lower than BRAF targeting therapies. Therefore MEK inhibitors are used as part of a combination therapy of BRAF mutated diseases [39].
3.3.2. Type III Transmembrane Receptor Tyrosine Kinase. Certain acral and mucosal subtypes of MM appear to show type III transmembrane receptor tyrosine kinase (KIT) activating mutations. A study in 2011 has shown that imatinib treatment is promising, particularly in patients with an exon 11 or 13 mutation [40]. Nilotinib has also been shown to be effective in patients who were intolerant, or whose disease has progressed after imatinib therapy, as well as those with brain metastases [41]. KIT therapy is still being refined but presents a possible treatment option for selected subsets of patients [39].

\subsection{Immunotherapy}

3.4.1. Interleukin 2. In the 90 s there was a breakthrough in the field of MM treatment. Following the therapies based on DNA-damaging agents, the newest treatment option for $\mathrm{MM}$ was immunotherapy in form of IL-2 [42]. It is a protein the size of $15,5 \mathrm{kDa}$ and one of the first extensively described and characterized cytokines. Its mode of action is the binding with a receptor consisting of 3 subunits (IL-2R $\alpha$, IL-2R $\beta$, and IL- $2 \mathrm{R} \gamma)$. The combination of these activated the proliferation of $\mathrm{T}, \mathrm{B}$, and $\mathrm{NK}$ cells, which are of vital importance for the homeostasis of the immune system. In 1998 the FDA approved the use of it as a therapeutic option. The drawback of such a therapy is numerous unwanted side effects (inflammatory response, nausea, diarrhoea, etc.) as well as low response rate [42].

3.4.2. Interferon. Interferons have been, in the past thirty years, among the plethora of drugs, tested for the treatment of $\mathrm{MM}$, both in randomised and nonrandomised studies. Of all the adjuvant options, the IFN- $\alpha$ therapy has proved the most efficient and has since been adopted as part of the standard treatment. It has a broad spectrum of positive effects on the immune system and can aid the removal of the melanoma cells, which might have remained after the operation. It also exhibits an antitumor activity in metastatic diseases [37].

3.4.3. Cytotoxic T-Lymphocyte-Associated Protein 4. Breakthroughs in immunotherapy have also enabled the use of Tcell activation regulation by blocking cytotoxic lymphocyte associated antigen-4 (CTLA-4) in MM therapy. Ipilimumab is a human IgG1 monoclonal antibody that demonstrated an improvement in overall survival through this mechanism even in patients with advanced MM $[39,43]$.

3.4.4. Programmed Death 1. Clinical benefit has also been seen in programmed death 1 (PD-1) blocking antibodies. Pembrolizumab and nivolumab are antibodies, used in the treatment of distant melanoma metastases. Nivolumab has successfully increased overall survival and one- and twoyear survival rates when compared to dacarbazine and ipilimumab. It appears to be very well tolerated, with mild and manageable unwanted side effects such as rash, diarrhoea, and pruritus [39].

Pembrolizumab is a humanized anti-PD-1 IgG4 antibody that has also demonstrated a clinical benefit in patients with advanced MM. It also appears to be well tolerated with few 
unwanted side effects. PD-1 pathway inhibiting drugs also show promise in haematological malignancies [39].

Clinically, both CTLA-4 and PD-1 directed monotherapies have proven benefit in advanced MM. Additionally, in preclinical mouse models, the combination of CTLA-4 and PD-1 blockade appeared to be synergistic, leading to the clinical development of this combination. The combination demonstrated increased toxicity, although most seems to be treatable and reversible with prompt intervention [39].

3.5. Adoptive Cell Immunotherapy (ACT). ACT refers to the process of administering autologous or allogenic tumourreactive $\mathrm{T}$ or $\mathrm{NK}$ cells to patients with the intent of achieving tumour regression. This process occurs through the isolation of lymphocytes with high affinity for tumour antigens, which can be selected ex vivo, stimulated, expanded, and infused back into the patient and represents an area of great promise in the treatment of metastatic MM. It has been shown that numerous antigen-specific $\mathrm{T}$ cells can be isolated from excised tumours in MM. The limitations of this approach are the potential logistical and technical hurdles from patient selection, tumour resection, and expansion of adequate numbers of viable tumour infiltrating lymphocyte (TIL) cultures. To address some of these, novel strategies, such as genetically modified T cells, are being developed [39].

\section{Preventive Approaches in Skin Cancer Treatment}

Regular check-ups for former patients of skin cancer should include active searching for tumour recurrences and also for newly acquired tumours and MM, for which they are more susceptible. These check-ups should offer an opportunity for treating actinic keratosis. Bleeding, ulcerating, or changing lesion biopsies should be performed at the same time. Primary care physicians should aim to discover malignancies at an early stage, when they are still small and easily treated. Preventive measures should be built around the most important etiological factor, namely, sunlight. Exposure to the latter should be reduced, in children and adults alike. Children should avoid unnecessary exposure to sunlight, if they must, then times before 10.00 and past 14.00 are most appropriate. Parents should be reminded of UV radiation hazards (sunburns) and also of chronic sun exposure manifestations, such as wrinkled and thickened skin, irregular pigmentations, actinic keratosis, and tumours. Covering the sun exposed skin is advisable at all times. Sunscreens protect from UVA and UVB radiation. They are proven to protect from actinic keratosis, but not necessarily from BCC. Also, they partially protect from sunburns, though this can mislead the user with regard to the received sun radiation. It has been noticed that many MM patients show suboptimal levels of vitamin D at diagnosis and that people with higher vitamin $\mathrm{D}$ levels have a lower MM-related mortality. The links and causality between the two, however, have not yet been established [17, 44].

\section{Nanotechnological Methods}

5.1. Nanomaterials and Their Attributes. For the treatment of skin cancer, many different types of nanoparticles have been studied. Some of these are liposomes, dendrimers, polymersomes, carbon-based nanoparticles, inorganic nanoparticles, and protein-based nanoparticles [45]. Some of these will be presented and further discussed in the following chapters. Also, a brief overview of all mentioned nanotechnological approaches in treating skin cancer can be seen in Figure 2.

Nanosystems can be made from different materials (organic, inorganic) which determine their properties. Recently there have been quite a few studies discussing the different new possibilities of combining pharmacological agents and diagnostic procedures [46, 47]. Some common properties of nanosystems include their size ranging from 1 to $100 \mathrm{~nm}$, design through methodologies that exhibit fundamental control over the physical and chemical attributes of molecular-scale structures, as well their possible combination to form larger structures [48-50]. Some of the other characteristics that emphasize the wide range of their possible use in medicine are related to the fact that the delivery systems based on these structures can be found on different polymeric structures that possess hydrophobic and/or hydrophilic components. This in turn helps to solve the problem of solubility and delivery of highly hydrophobic anticancer drugs via the bloodstream [51]. We know that conventional drug delivery systems (DDSs) are often accompanied by systemic unwanted side effects that are mainly attributable to their nonspecific biodistribution and uncontrollable drug release characteristics. However, functionalized nanomaterials can increase the target specificity as well as the uptake and selective accumulation near a tumour due to the enhanced permeability and retention (EPR) effect $[52,53]$. This in turn leads to lower drug doses and fewer unwanted side effects on healthy tissues [54, 55]. These systems can, because of their size, circumvent filtration through the kidneys and therefore stay longer in the bloodstream. With specific adjustments (e.g., PEGylation) their half time can also be increased. Another benefit is that because of their high capacity, it could be possible to use drug carriers with more than one drug in combination therapy. Furthermore, drugs are, as stated previously, with the help of these carriers protected from a wide range of factors (physical and chemical changes in the body, $\mathrm{pH}$ changes, ionic strength, etc.), the premature decomposition due to enzymatic activity, or activation of the immune system $[48,56,57]$.

5.2. Methods to Achieve Controlled Drug Release. The release of the drug from the carrier can be controlled via external or internal stimuli $[58,59]$. The release is mediated by changes in $\mathrm{pH}$ (lower in a biochemically more active tumour), temperature (higher in the tumour), redox potential, biological macromolecules (enzymes, glucose, antigens, etc.), light, magnetic field, ultrasound, and a combination of these stimuli $[60,61]$. Useful diagnostic modalities are MRI with $\mathrm{T} 1$ and/or T2 sensitive agents, fluorescein markers, and radionuclides $[56,57]$.

5.2.1. Endothelium Targeting. Current nanoparticle aided drug delivery is at its most useful in solid tumour therapy $[62,63]$. Molecular biology methodology allows us to uncover 


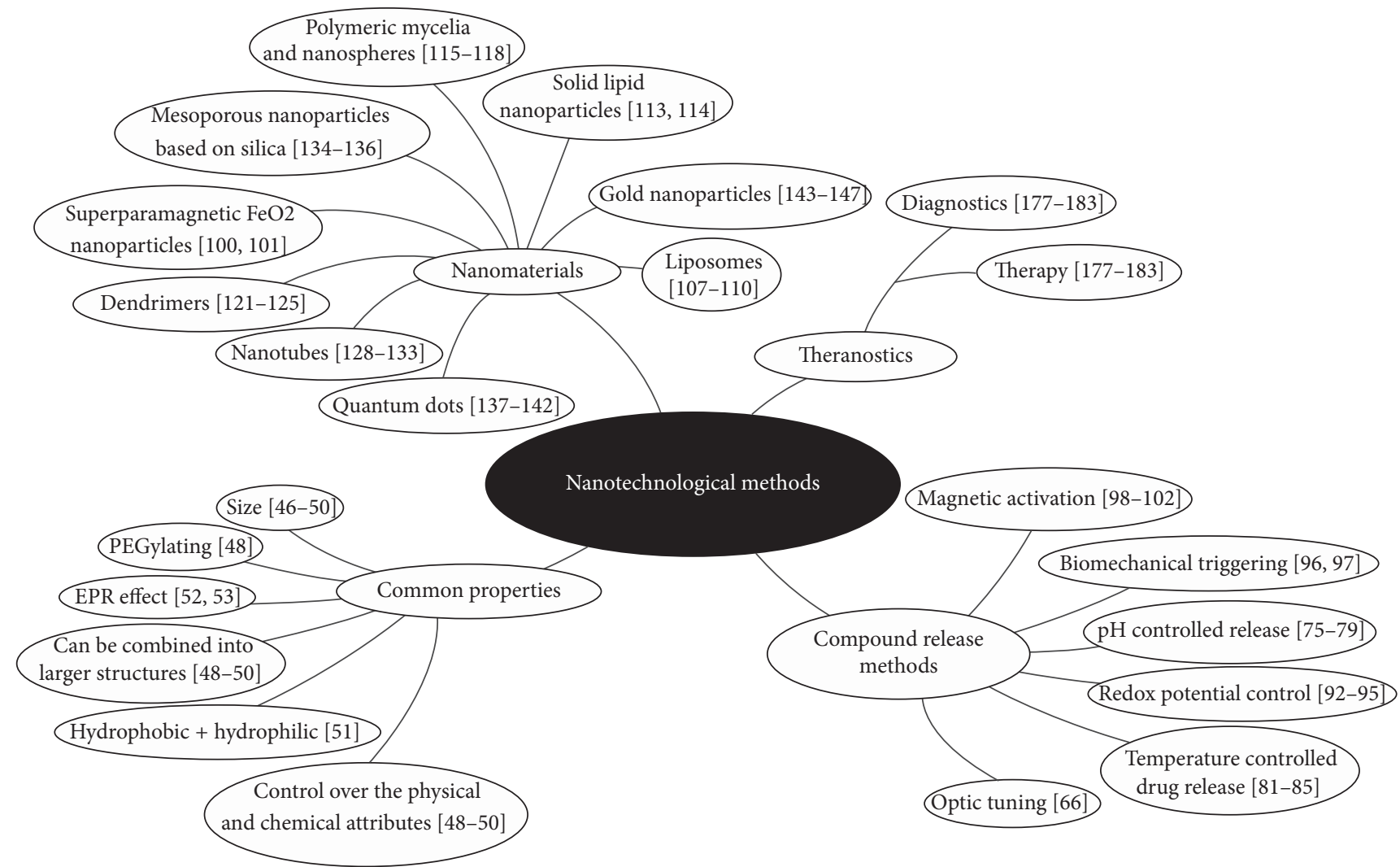

FIGURE 2: Graphically depicted properties and methods of nanotechnology in skin cancer treatment.

potential targets within tumour vasculature, such as integrins, which have a role in angiogenesis [64, 65]. Integrins bind to the tripeptide Arg-Gly-Asp (RGD) inclusive sequences and have been included into a cyclic nanopeptide RGD-4C, which binds to integrins $v \beta 3$ in $v \beta 5$ without any cross-reactivity with thrombocyte integrins and other ubiquitous receptors [66]. Coupling RGD-4C with doxorubicin increases the latter's chemotherapeutical efficacy, which grants a decreased hepatotoxicity and cardiotoxicity [67]. Other binding sequences also exist, such as histidinetryptophan-glycine-phenylalanine (HWGF), which actively binds to matrical metalloproteinases 2 and 9, which enhances adenoviral tropism for big blood vessel endothelial and smooth muscle cells [68]. Another such molecule is the NGR hexapeptide, which binds to $\mathrm{N}$ angiogenic endothelial cell peptidases [66]. Coupling doxorubicin and melphalan with TNF- $\alpha$ increases the chemoreactivity of chemotherapeutics against murine tumours eight- to tenfold [69]. Another antiangiogenic solid tumour treatment approach uses a synthetic $\mathrm{v} \beta 3$ analogue with the intention of targeted delivery of therapeutic genes complexed with cation nanoparticles in tumour endothelial cells [70]. A similar approach is used for location specific MR imaging with $\mathrm{v} \beta 3$ targeted paramagnetic nanoparticles, which can discover early tumour angiogenesis $[66,71]$.

Other methods include selective targeting of blood and lymphatic vessels with peptide covered quantum dots [72] and also with NGR covered liposomes for tumour blood vessel closure [73].
Other important endothelial targets for therapeutic drug delivery include cell adhesion molecules (CAMs) (e.g., ICAM-1 and PECAM-1). Anti-CAM nanoparticles can deliver compounds to pulmonary and heart endothelium in vivo $[66,74]$.

5.2.2. pH Controlled Drug Release. Some human tissues have, under certain conditions such as cancer or inflammation, a lower $\mathrm{pH}$ than healthy tissues $[75,76]$. These $\mathrm{pH}$ differences are a useable stimulus for property modulation of certain materials, which can be used for specific reactions, such as controlled drug release [77].

An example of this principle is mesoporous silica nanoparticles (MSNP), which can, in intravenous use, release the incorporated drug before they reach the target area. This is an undesired effect, since the potentially toxic drugs damage healthy cells before they reach the cancer cells. Difference in $\mathrm{pH}$ can be used as a release stimulus, because the pores present in silica nanoparticles can be blocked by $\mathrm{pH}$ sensitive functional groups and hence can be unblocked when $\mathrm{pH}$ reaches a low enough value $[78,79]$. For this, we use different classes of $\mathrm{pH}$ sensitive molecules, which efficiently close the pores $[78,79]$.

5.2.3. Temperature Controlled Drug Release. Heat is another stimulus that can be used for triggered release of molecules from MSNP [80, 81]. Temperature of many tumours is slightly higher than normal body temperature. With this 
phenomenon in mind, we can use temperature responsive polymers as the pores' plugs $[82,83]$. A commonly used temperature responsive polymer is poly $(\mathrm{N}$-isopropylacrylamide) (PNIPAM) [84]. Volume of the said polymer can change in water, at the so-called low critical solution temperature (LCST) [85]. Below this temperature, the PNIPAM chains are hydrated and hence extended. This can, in connection with MSNPs, prevent the drug release from the pores. At the temperatures above the LCST, PNIPAM chains dehydrate, which causes them to contract, and release the drug held within [86]. Pure PNIPAM is usually not used in such drug delivery, because its LCST is about $32^{\circ} \mathrm{C}$, which is, in light of the higher normal body temperature, inappropriate, because it would keep the pores open at all times. We can, however, raise the LCST by copolymerization with other monomers (acrylamide, or $\mathrm{N}$-isopropylmethacrylamide) [87, 88] to about $37^{\circ} \mathrm{C}[89,90]$. By using this copolymerized PNIPAM, one can raise the releasing temperature to above $37^{\circ} \mathrm{C}$. Higher temperatures can also be achieved by external stimulation, for example, magnetic field, or light, which interact with the inorganic nanoparticles included in or bound to the MSNP. An interesting use of this principle is a combination of iron oxide nanoparticles and PNIPAM. Exposing the said system to an outer electromagnetic field causes a raise in the local temperature around the nanoparticles, which subsequently leads to a phase transformation of PNIPAM, which enables the release of the drug [91].

5.2.4. Redox Potential Control. Intracellular and extracellular environments of living tissues exhibit different redox potentials. Due to a 100-1000-fold increase of glutathione (GSH) levels within tumour cells compared to the extracellular levels, a natural redox potential may occur [86]. These potential differences can be used for triggering the drug release from nanoparticles within the cancer cells (inside trigger). Here, similarly to the $\mathrm{pH}$ system, a redox responsive system was devised, where a variety of nanoplugs may be used. Particles used for this purpose include $\mathrm{CdS}$ [92], $\mathrm{Fe}_{3} \mathrm{O}_{4}$ [93], or gold nanoparticles [94], but also MSNP, covalently bound to biomolecules. The typical redox responsive plugMSNP bond is a disulphide one [95]. Due to high intracellular GSH concentration, the disulphide bridge dissolves, which causes the emergence of two thiol groups on the targeted tumour site, because GSH acts as a reducing agent [95]. Low blood reducing agent levels allow for the disulphide connections to remain intact.

5.2.5. Biomechanical Triggering. Biocompatible and bioactive molecules are, due to their responsiveness to bodily stimuli, frequently used for controlled drug release. The most often used biomolecules are bioenzymes (e.g., $\beta$-D-galactosidase [96]), glucose, antigens, and aptamer targets [97]. Enzyme responsive nanogates are, due to anomalous elevation of enzymatic activity in certain unhealthy tissues, a feasible option for MSNP pore closure.

5.2.6. Optic Tuning. Light can be, thanks to its specific physical properties, used as a trigger for releasing encapsulated molecules from micro- and nanosystems. It is possible, within the MSNP frame, to successfully include light sensitive molecules, which gives us a light-responsive drug delivery system. The light-responsive MSNP state modulation can be reversible or irreversible, which is usually dependent on the manner of chromophore bonding to MSNPs. The photochromic nanoparticle component isomerisation is usually followed by heat or visible reisomerisation. Light, used as the stimulant, has usually a wavelength of 300-400 nm, while we use visible light $(\lambda>400 \mathrm{~nm})$ in order to achieve reisomerisation. The reversible pore plugging and unplugging offers some distinct advantages, because it enables the possibility of using complex drug releasing mechanisms [66].

5.2.7. Magnetic Activation. Magnetic nanoparticles (MNPs), sized $10-100 \mathrm{~nm}$, which are responsive to a magnetic field, are used as multimodal drug delivery systems, based on their superparamagnetic properties [98, 99]. Materials, used most often, are iron oxide nanoparticles (IONP) [100, 101]. They are used in two main forms, namely, magnetite $\left(\mathrm{Fe}_{3} \mathrm{O}_{4}\right)$ and its oxidised metabolite, maghemite $\left(\gamma-\mathrm{Fe}_{2} \mathrm{O}_{3}\right)$ [102]. The magnetic field is created using strong permanent magnets, usually of the neodymium kind. In order to localize the nanoparticles in the target tissue, one must focus the magnetic field on a specific area to which the IONP (with the incorporated drug) are drawn $[103,104]$. The power and location of the magnetic field are adaptable, which means that we may control the nanoparticle accumulation, which lessens the unwanted cytotoxic effects on healthy tissues [105]. The magnetic field gradient is dependent on local resistance (caused by blood flow and depth of the targeted site), which makes these nanoparticles more efficient in areas with less blood flow, and closer to the surface. IONP are, in general, coated with hydrophobic polymers, which makes them less susceptible to opsonization, which, in turn, prolongs the circulation time and secures the binding surface for drug molecules, or specific target ligands [106]. MSNP in combination with magnetic nanoparticles represent a promising alternative drug delivery method, one which is advantageous due to its high capacity, target specificity, and magnetic properties that are useful in targeting and controlled drug release [91].

\subsection{Common Nanoparticulate Systems}

5.3.1. Liposomes. Liposomes are phospholipid vesicles ranging in size mostly from 50 to $100 \mathrm{~nm}$. Their membrane is double layered, quite similar to biological ones, with an internal aqueous phase [107]. Liposomes can be divided according to their size and number of layers into multi-, oligo-, or unilamellar [108]. The aqueous core can be used for the encapsulation of water soluble drugs, whereas the lipid membrane can act as a carrier for hydrophobic and amphiphilic compounds [108]. To avoid the reticuloendothelial system (RES) after intravenous injection special PEGylated liposomes have been developed (sometimes called "stealth liposomes"), which reduce the clearance of the active compound and prolong the circulation half time. Other positive features of liposomes are very good circulation, penetration, and diffusion qualities $[107,108]$. The surface of the vesicles can be bound with ligands or polymers, 
which extensively increases their specificity for drug delivery. Research has already shown that liposomes gather close to tumour vessels in the interstitial fluid. There are currently a few different types of liposomes used as drug carriers for anticancer therapy. One of these therapies is also the treatment of MM $[109,110]$.

The advance in cationic liposomes has led to a successful delivery of siRNA $[109,111]$. Theranostic liposomes have also been developed, which can be equipped with an array of different nanoparticles as well as an active compound. Some are used in anticancer therapy with a special vitamin $\mathrm{E}$ based coating called D- $\alpha$-tocopherol polyethylene glycol succinate (TPGS). Liposomes can be modified to include magnetic elements, which allow for real time monitoring or for the entrapment of gasses and drugs [45].

Liposomes filled with doxorubicin, cisplatin, oxaliplatin, camptothecin, and other drugs have reached higher cytotoxicity and decreased adverse effects, due to targeted release [45]. According to a study conducted by Fang et al. [112], flexible liposomes increased aminolevulinic acid penetrance better than lysosomes, though both increased penetrance in comparison to the control treatment. Niosomes (nonionic surfactant vesicles) filled with 5-fluorouracil produced an eightfold increase in cytotoxicity, compared to an aqueous solution [45].

5.3.2. Solid Lipid Nanoparticles. Solid lipid nanoparticles (SLNs) were presented in 1990 as an alternative to liposomes, emulsion, and polymeric nanoparticles as drug carriers. They are very stable and therefore provide protection from degradation of the drug as well as enable easy control over drug release $[113,114]$. Organic solvents are not required for their development. They are biodegradable, biocompatible and very rarely toxic. Furthermore, their production and sterilization are not profoundly difficult. It has been shown that with the use of these nanoparticles the in vitro and in vivo efficacy of the drug docetaxel in colorectal cancer and MM has increased [45].

5.3.3. Polymeric Mycelia and Nanospheres. Polymeric mycelia are structures that consist of two or more polymeric chains with varying degrees of hydrophobicity [115, 116]. Mycelia spontaneously converge into a characteristic (mycelial) structure, which consist of a centre and a shell with different properties. The hydrophobic parts form the centre, which decreases their exposure to an aqueous environment, while the hydrophilic parts form the shell that remain in contact with the aqueous environment, thereby stabilizing the centre [117]. The usual size of pharmaceutically useful mycelia is $10-80 \mathrm{~nm}$. Since they are smaller in size than liposomes they have a shorter circulation time and are more inclined to enter tumours, due to the EPR effect [118]. Drugs with low solubility can be transported in the hydrophobic centre, while the hydrophilic shell offers sterical protection to the mycelium, which reduces systemic toxicity. Its usefulness can be improved with the inclusion of ligands into the shell (e.g., antibodies, peptides, nucleic acid aptamers, carbohydrates, and other molecules) [117].
Polymeric mycelia are usually more stable in the bloodstream than liposomes and other surface mycelia [118]. They can be used to deliver two or more active ingredients in combined therapy, due to their considerable size. Paramagnetic metals, like gadolinium or manganese that are often used as contrast agents, can be inserted into the mycelia. As such, they can also be used in imaging $[119,120]$.

Polymeric nanospheres are insoluble colloid nano- or microparticles with a polymeric centre, about $10-1000 \mathrm{~nm}$ in size. They are usually used as $\mathrm{pH}$ sensitive pharmaceutical delivery systems and are administered per os [45].

5.3.4. Dendrimers. Dendrimers are unimolecular monodisperse synthetic polymers that possess a layered structure and are sized below $15 \mathrm{~nm}$. They consist of a core, made of repeating units and various terminal groups, that determine their 3D structure $[121,122]$. They can be made to deliver hydrophilic or hydrophobic pharmaceuticals, nucleic acids, and imaging contrasts, due to their well-defined size, molecular mass, monodispersity, multivalency, the number of available internal compartments, high level of branching, and many functional groups on the surface [121]. Dendrimer targeted ligands are capable of specific targeting and tumour elimination $[122,123]$. These ligands include oligosaccharides, polysaccharides, oligopeptides, semiunsaturated fatty acids, folates, and tumour associated antigens. The downside to dendrimers is the difficulty to release the pharmaceutical in a controlled manner. New developments in dendrimer and polymeric chemistry have produced a new type of molecule, called dendronized polymers [124]. Dendronized polymers are linear polymers that carry dendrons on every repeated unit and have an increased circulation time, which is advantageous for drug delivery. A drug can also be bound to a degradable link that can be used to control the release of the drug [125-127].

5.3.5. Nanotubes. Carbon nanotubes are carbon allotropes, composed of one or more coaxial sheaths of graphite only a few atom layers thick and folded into cylinders [128]. They can be single-walled or multiwalled and exhibit extraordinary physical, photochemical, and electrochemical properties $[128,129]$. Being semiconductors, they are often used as biosensors [130, 131]. They can also be used as drug transporters or as a basis for tissue regeneration [132]. Single wall carbon fibre nanotubes (SWCNT) that are capable of tumour targeting are synthesized by covalently binding several copies of tumour specific monoclonal antibodies, radiating ion chelates and fluorescent probes to the tubes [132]. This system can then be filled with molecules of an antitumor drug. Since this does not require covalent bonding, the antibodies capability to bind to tumour cells is not impaired by a greater quantity of the drug [133]. They can be used to carry gadolinium atoms, which is useful in MRI imaging of tumours. They can also be equipped with agonists or antagonists to various receptors on their surface, which can be used to treat the tumour [45].

5.3.6. Mesoporous Nanoparticles Based on Silica. Mesoporous silica is an effective drug transporter. In comparison to 
common organic transporters, they have a variable particle size, a different morphology, an even and adjustable pore size, high chemical and mechanical stability, a large surface, pore volume, a great drug transporting capacity, and simple surface functionality $[45,101,134-136]$.

5.3.7. Quantum Dots. Quantum dots are colloid fluorescent semiconductive nanocrystals with a size of $2-10 \mathrm{~nm}$. They have a broad absorption spectrum and a symmetrical and narrow emission, usually in the visible spectrum near the infrared area [137]. The central core of the quantum dots usually consists of a combination of elements of the II-VI groups (e.g., zinc, cadmium, selenium, and tellurium), or the III-V groups (e.g., arsenic and phosphorus) of the periodic table, enveloped by a sheath of $\mathrm{ZnS}[137,138]$. By changing the size and composition, we can control the emission spectrum and quantum results. They are suitable for high-intensity, long-term, multitarget bioimaging applications, due to their photostability [137-140].

We can select a specific colour of emission of a quantum dot. In order to detect MM, however, we have to create a hydrophilic surface and attach a ligand that can be used to detect the tumour [141]. These ligands can be antibodies, peptides, smaller molecules, or inhibitors [141, 142].

Biocompatibility can be increased by adding silicon or other biocompatible polymer sheaths, which also decreases their toxicity.

5.3.8. Gold Nanoparticles. Gold nanoparticles are metal nanoparticles that can be formed into various geometric structures, such as nanospheres, nanocages, and nanorods of $1-150 \mathrm{~nm}$ in size [143]. These particles show a combination of physical, chemical, optical, and electronic properties that are not found in other biomedical nanomaterials and are applicable in gene delivery, as contrasting agents and as part of drug delivery systems $[144,145]$. The advantages of gold nanoparticles lie in the simple synthesis of various particle sizes, confirmed biocompatibility, and the capability to conjugate with other biomolecules without changing their biological properties [146, 147]. Particles under $50 \mathrm{~nm}$ can pass the blood-brain barrier. They are also nontoxic and biocompatible, as they do not induce an allergic or immune response of any kind [45].

\subsubsection{Superparamagnetic Ferrous Oxide Nanoparticles and} Thermal Therapy. These are nanoparticles composed of ferrous oxide, covered with a sheath, that enables stability, prevents agglomeration, and enables other functions (e.g., targeting, binding of active ingredients) $[100,101]$. They can very effectively be synthesized by decomposing iron precursors while being immersed in oleic acid. These particles, however, are hydrophobic and need further manipulation to achieve hydrophilicity [148].

These nanoparticles gain a large magnetic momentum in an external magnetic field and are therefore considered as superparamagnetic materials, which makes them interesting for biomedical use [149]. They can be used as a contrast in MRI, since they produce a large quantity of contrast per unit, which means that a small dose of particles is sufficient for the imaging, which decreases toxicity $[150,151]$. These particles are capable of transforming the energy of an external magnetic field into heat, which can be used to treat tumours, since tumour cells are more susceptible to high temperatures than normal human cells [152]. Their surface can be augmented with various functional groups, increasing biocompatibility and biodegradability, which further increases their usefulness. Polymers like cellulose, dextran, PEG, or PLGA that can also be added to the surface increase their biocompatibility and biodegradability [153-155].

In past decades, cancer treatment has been mostly based on chemotherapy, radiation, and/or surgery. Certain additional kinds of therapy, for example, therapeutic hyperthermia, have been to some degree successful but have yet to become a part of the standard variety of therapies [156]. The reason for this lies in the difficulty of an accurate differentiation between normal and cancer tissue, but also in the failure of specific targeting of tumours, as well as insufficient understanding with regard to hyperthermic cytotoxicity [157].

In 1991 Roizin-Towle and Pirro discovered that one can destroy all cells with an appropriate amount of heat. However, compared to normal cells, in vitro experiments have not shown any increased sensitivity of tumour cells to heat. This differs in radiotherapy and chemotherapy. The aforementioned authors have shown that, in thermal therapy, one needs to achieve a high enough concentration of active particles (ones that are able to emit heat) in the immediate proximity of the tumour cells [156]. Although there is a noticeable difference in vivo, there is still a lack of clinically available technology that would make it possible for the active particles to be accurately applied in the effective proximity of the tumours [157].

Hyperthermia is only effective in treating tumours if certain conditions are met $[158,159]$. These are a high enough concentration of nanoparticles in the tumour, which is also considerably higher than that in the surrounding healthy tissue, and a sufficiently high specific absorption particle level that is responsible for a sufficiently high intratumoural amount of applied heat, which must be tolerable for the normal tissues [157].

There are three currently researched methods of therapeutically heating nanoparticles. These are optical laser heating, ultrasound heating of small bubbles, and heating of metal nanoparticles, aided by an alternating magnetic field [159-161]. Naturally, there are pros and cons to each of the aforementioned methods. The optical method is an effective way of heating the particles but is limited by the depth related weakening of the laser. Ultrasound is capable of targeted energy focus, but the delivered energy is not constant because of the different sound velocity in different tissues, and the probe opening is also rather small. Magnetic nanoparticles can be effectively heated at any depth, and they can also be used in diagnostic imaging procedures [157].

Hyperthermia can also be used as a form of adjuvant therapy, because it is well-known that exposure of tumour cells to even a slightly raised temperature increases the sensitivity of these cells for chemotherapy and radiotherapy [162-164]. One of the oldest uses of heat application can be 
found in treating intraperitoneal ovary cancer metastases, where a higher effectiveness of certain chemotherapeutics has been proven. However, there are limitations to this method as well, for it is impossible to deliver the same amount of heat to all the metastases [157].

Currently, chemotherapy is only an adjuvant therapy to radiotherapy in solid tumours, because selective delivery of the chemotherapeutics to the tumours is lacking, which could be changed with the usage of localized hyperthermia $[160,161$, 165]. In this way, the effectiveness of the chemotherapeutics could be increased, which would allow for a lower dosage of the drug in question, which also means that the toxicity in the nontumour tissue would decrease [157].

The combination of chemotherapeutics and hyperthermia can be adjusted, depending on the type and site of the tumour, also for the dose of the drug, and temperature. Much also depends on the chemotherapeutic in question, because the highest effectiveness of the alkylating agents is achieved at $41,5^{\circ} \mathrm{C}$, while some other drugs (like cisplatin) can be effective at lower temperatures as well. Raising the temperature to 2$3^{\circ} \mathrm{C}$ above the basal level raises the local blood flow in the heated areas during and also for a while after heating, which allows for the accumulation of the chemotherapeutics near the heated areas [157].

Additionally, hyperthermia can improve radiotherapy, because ionizing radiation damages the DNA, while heat damages proteins, responsible for the repair of the former. Moreover, hyperthermia can also destroy cells in the hypoxic areas of the tumours, those that are more resistant to radiation [157].

One can heat the nanoparticles in a variety of ways, such as with dielectric energy losses in a material with low electrical conductivity, losses of energy of the Foucault currents in a material with high electroconductivity, frictional heating induced with physical spinning of an anisotropic magnetic particle, and hysteretic losses in a magnetic material [156]. The first two mechanisms can, however, cause unwanted heating of the normal tissue, which makes them clinically less interesting [156].

Frictional heating is possible because of the physical spinning of an anisotropic magnetic particle in an alternating magnetic field, which leads to energy losses. Such heating may induce mechanical cell damage [157]. Hysteretic energy loss is possible because of an irreversible particle magnetization in an alternating magnetic field [156].

5.4. Nanotechnological Approaches in Treating Skin Cancer. In the field of MM research there have been many new studies in which researchers tried combining new nanotechnological advances with conventional methods and treatment procedures (chemotherapy, photodynamic therapy, etc.) for developing new potential ways of treatment [166]. For example, the Food and Drug Administration (FDA) has permitted clinical trials for at least two novel nanoparticle based formulations with incorporated antitumor drugs, for example, Doxil (Janssen Biotech, Horsham, PA, USA) and Nab-paclitaxel (Abraxane).

Maria Bernadete R Pierre et al. determined that liposomes can reach the appropriate depth to treat skin cancer (epidermis, dermis) by transdermal application [167]. In a study that included 26 patients, Bedikian et al. achieved an $31 \%$ improvement over metastatic malignant lymphoma, using liposomes with vincristine, compared to the control group [168].

Huber et al. investigated the possibility of using doxorubicin (DOX) filled cationic solid lipid nanoparticles (DOXSLN) to increase distribution and tumour penetration of DOX. In vivo DOX-SLN iontophoresis was effective in inhibiting tumour growth [169].

Mycelia were used in a small-scale phase 1 study, which showed that patients with MM tolerate NC6004 (Nanoplatin) well [170].

Dendrimers were successfully used in immunotherapy, immunoradiotherapy, and other tumour treatments, among others in MM and SCC. They can also be used for diagnostic imaging of cancer cells (e.g., MRI). Gadolinium dendrimer conjugates were shown to enable selective large-scale targeting and imaging of tumours $[45,171,172]$.

A low solubility antitumor compound camptothecin has been loaded into polyvinyl alcohol-functionalized multiwalled nanotubes. The results showed that such a combination could be used to treat breast and skin cancer [173].

Gold nanoparticles can be used to increase cell and tissue sensitivity to therapy and to guide and control surgical procedures. Various active ingredients, including proteins, DNA, and smaller drug molecules, can be bound to the surface of gold nanoparticles, which leads to a therapeutic effect in different kinds of tumours, including MM [174, 175]. They are also excellent markers for biosensors, as they can be detected in many ways, such as optic absorption, fluorescence, and electrical conductivity. Together with reflex microscopy, antibody-bound gold nanoparticles enable highly sensitive cancer imaging $[145,174,175]$.

Superparamagnetic ferrous oxide thermal therapy can be used as an adjuvant therapy in order to sensitise cancer cells to chemotherapy or radiotherapy. Rao et al. have additionally shown that epirubicin loaded superparamagnetic ferrous oxide particles are also suitable for transdermal skin cancer therapy [176].

5.5. Theranostics: An Inspiring Approach Adjusted to Future Cancer Treatment Needs. The term theranostics was first used by Funkhouser in 2002 [177]. By definition, theranostics provides a combination of diagnostic and therapeutic capabilities, and as such shows great promise to significantly contribute to the advancement of personalized medicine $[46,56]$. Theranostic nanomedicine is an interdisciplinary field, which combines the expertise of genomics, proteomics, metabolomics, biophysics, pharmacology, pharmaceutical technology, and so forth. The main aim is to develop an efficient and safe nanosystem that is composed of a high capacity nanoplatform that can carry therapeutic agents and at the same time include a diagnostic component, hence combining both imaging and therapeutic functions [178, 179]. Release of the therapeutic agent on target site could be spontaneous or specially specified (e.g., influence of external or internal chemical and physical stimuli). Such systems could be guided, followed, and monitored to the point of determining the 
pharmacodynamic and pharmacokinetic properties of the drug in real time $[47,178,179]$. Moreover, with the selection of the appropriate nanoplatform, one could bypass certain pharmacokinetic limitations of drugs, which could lead to an easier mode of application and, with regard to the aim of reducing systemic toxicity, improve selectivity of targeting only diseased tissues. Due to all mentioned, this field shows most likely the biggest potential in oncology [166]. A great example of that is the sheer number of published studies and articles. Orecchioni et al., for example, recently reviewed the latest studies about the promising usage of graphene as a nanoplatform in cancer therapy [180]. Furthermore, von Felbert et al. recently published their study about improving the specificity of drug transporters as theranostic agents. They developed a homogenous phototheranostic system which combines optic imaging, photodynamic therapy, and immunotherapy [181]. Last but not least, there were also some newer theranostic advances in treating skin cancer. For example, in the study described by Vannucci et al. [182], they have developed a nanoparticle based on the heavy chain of the human protein ferritin and coated it with melanocyte stimulating hormone (MSH), with which they assured tissue specificity. The as-prepared nanoparticles were also coated with PEG molecules, which prevented their binding to unwanted receptors. They also added the fluorescent dye rhodamine as the diagnostic component [182]. Another example of theranostics in skin cancer treatment has been presented in the study by Ma et al., where they used lipid nanomicelles as the carrier for docetaxel. For the diagnostic monitoring they used fluorescent dye $1,1^{\prime}$-dioctadecyl-3,3,3',3'-tetramethyl indotricarbocyanine iodide (DiR) [183]. Both examples show very promising results that could, in a not that far future, make them applicable also in the clinics.

\section{Potential Impact of Nanotechnology on Future Skin Cancer Treatment}

Novel treatment approaches, regardless of the disease, are meant to be more efficient, cheaper, and without any sacrifice of patient safety, if not even improving it. To achieve the latter, an ideal treatment should be developed taking into account good patient compliance, a better overall treatment efficiency, a very low possible toxicity, and very high yields of reaching the targeted site in the body per unit mass of the medicine. Nanotechnology based formulations can provide all mentioned. They can be more efficient, since they can be decorated with targeting moieties (e.g., antibodies) [184], and at the same time deliver and release the payload in a controlled manner [185]. Both mentioned leads also to a lowered toxicity, since lower doses are necessary to achieve the same effect [186], as well as the targeting and controlled release only at the targeted site, and renders the toxicity highly localized. The latter is also in direct relation to the high yields of the delivery [187]. Knowing these potential advantages of such formulations, it comes to no surprise that these are heavily researched and that there is a high demand for their uptake into clinical practice as soon proven safe. And indeed, there are at least two already approved nanotechnology based formulations used in cancer treatment. As mentioned already above, these are Doxil (Janssen Biotech, Horsham, PA, USA), a doxorubicin containing liposome injection, and Nab-paclitaxel (Abraxane), which contains paclitaxel bound to albumin nanoparticles $(2 r \approx 130 \mathrm{~nm})$.

Considering all mentioned in regard of skin cancer treatment, there are some promising (at least research) trends that could well mean significant improvements in the potential treatment outcome for skin cancer patients. Several different forms of novel nanosized formulations have been already developed and are presently in different stages of testing [2, 188, 189]. Among others, various lipid-based particles (e.g., micelles, solid lipid particles) are particularly popular [167-169]. These not only have often the ability to outsmart the host defence of the organism, which for itself leads to improved yields of the payload delivery [190], but at the same time provide different other targeting approaches to improve this yield even more. Carbon nanostructures are still among the most researched types of nanostructures for biomedical applications [191, 192], especially considering the high interest in them for various other applications (e.g., molecular electronics), a vast number of modification approaches are available for them [193, 194], making them interesting candidates for future effective cancer treatment [173].

Finally, we believe that the most promising future treatment approaches lie in the field of theranostics, which combines all the right "ingredients" to meet all the requirements of the ideal treatment approach. As such, several novel treatment solutions in skin cancer were already studied [182, $183]$.

It is worth noting that, from our perspective, MNPs seem to be among the most promising nanoparticulate agents, especially in the treatment of "hard-to-treat" cancer forms (e.g., MM). Among MNPs, the most commonly used particles are certainly based on iron oxides [100, 101]. The latter were combined with various drugs (e.g., epirubicin) [176] and are on their own capable of being used to induce magnetic hyperthermia $[158,159]$, and since they are mostly functionalized in order to prevent agglomeration [195], their surface is suitable for anchoring different targeting moieties (e.g., antibodies) [196, 197].

\section{Conclusions}

New nanotechnological materials appear to be efficient cytostatic delivery systems, capable of tumour targeting and thereby decreasing adverse effects, increasing therapy effectiveness, and increasing the survival of skin cancer patients. New pharmaceuticals combined with improved delivery systems therefore present a developing field that will surely improve skin cancer treatment for patients, by improving either the quality of life or survival of affected patients. Finally, through this development, medical professionals will gain new and accurate diagnostic and effective therapeutic options. The advent of new delivery systems can already be seen in the use of transdermal patches [176].

\section{Abbreviations}

BCC: Basal cell carcinoma

SCC: Squamous cell carcinoma 
CSC: $\quad$ Cancer stem cell

CMC: Circulating melanoma cells

EPR: $\quad$ Enhanced permeability and retention

HPV: Human papilloma virus

MM: Malignant melanoma

UVA: Ultraviolet A

UVB: Ultraviolet B

TPGS: D-Alpha-tocopheryl polyethylene glycol

1000 succinate monoester

EDC: Electrodessication and curettage

MSNP: Mesoporous silica nanoparticles

PCR: Polymerase chain reaction

ISH: In situ hybridization

PD: $\quad$ Programmed death

SWCNT: Single wall carbon nanotubes

IONP: Iron oxide nanoparticles magnetic

LCST: Lower critical solution temperature

KIT: $\quad$ Type III transmembrane receptor tyrosine kinase

MEK: Mitogen-activated protein kinase

BRAF: Serine/threonine-protein kinase

CTLA-4: Cytotoxic T-lymphocyte-associated protein 4

IL-2: $\quad$ Interleukin 2.

\section{Disclosure}

Kristjan Orthaber, Matevž Pristovnik, and Kristijan Skok share the first authorship.

\section{Competing Interests}

All authors state that there is no conflict of interests.

\section{Authors' Contributions}

Kristjan Orthaber, Matevž Pristovnik, and Kristijan Skok contributed equally to this work.

\section{Acknowledgments}

The authors acknowledge the financial support from the Slovenian Research Agency (Grant no. P-0036 in J2-6760).

\section{References}

[1] J. D’Orazio, S. Jarrett, A. Amaro-Ortiz, and T. Scott, "UV radiation and the skin," International Journal of Molecular Sciences, vol. 14, no. 6, pp. 12222-12248, 2013.

[2] M. C. F. Simões, J. J. S. Sousa, and A. A. C. C. Pais, "Skin cancer and new treatment perspectives: a review," Cancer Letters, vol. 357, no. 1, pp. 8-42, 2015.

[3] Medical Center University of California, Nonmelanoma Skin Cancer vs. Melanoma, 2007.

[4] D. L. Narayanan, R. N. Saladi, and J. L. Fox, "Ultraviolet radiation and skin cancer," International Journal of Dermatology, vol. 49, no. 9, pp. 978-986, 2010.

[5] J. S. Rhee, B. A. Matthews, M. Neuburg, B. R. Logan, M. Burzynski, and A. B. Nattinger, "The skin cancer index: clinical responsiveness and predictors of quality of life," The Laryngoscope, vol. 117, no. 3, pp. 399-405, 2007.

[6] L. O'Driscoll, J. McMorrow, P. Doolan et al., "Investigation of the molecular profile of basal cell carcinoma using whole genome microarrays," Molecular Cancer, vol. 5, article 74, 2006.

[7] L. H. Goldberg, "Basal cell carcinoma," Lancet, vol. 347, no. 9002, pp. 663-667, 1996.

[8] A. Lomas, J. Leonardi-Bee, and F. Bath-Hextall, "A systematic review of worldwide incidence of nonmelanoma skin cancer," British Journal of Dermatology, vol. 166, no. 5, pp. 1069-1080, 2012.

[9] C. Garbe, D. Schadendorf, W. Stolz et al., "Short German guidelines: malignant melanoma," Journal der Deutschen Dermatologischen Gesellschaft, vol. 6, no. 1, pp. S9-S15, 2008.

[10] Slora, "Maligni melanom (C43): Slora," 2016, http://www.slora .si/c/document_library/get_file?uuid=c2e610c7-5353-40dd-93e9lb1b2320e3e1\&groupId=11561.

[11] S. Sachdeva, "Fitzpatrick skin typing: applications in dermatology," Indian Journal of Dermatology, Venereology and Leprology, vol. 75, no. 1, pp. 93-96, 2009.

[12] T. B. Fitzpatrick and A. J. Sober, "Sunlight and skin cancer," New England Journal of Medicine, vol. 313, no. 13, pp. 818-820, 1985.

[13] Onkološki Inštitut Ljubljana, Rak v Sloveniji 2012, Edited by M. Žakelj Primic, Onkološki inštitut Ljubljana, Epidemiologija in Register Raka, Register Raka Republike Slovenije, Ljubljana, Slovenia, 2015.

[14] J. Califano and M. Nance, "Malignant Melanoma," Facial Plastic Surgery Clinics of North America, vol. 17, no. 3, pp. 337-348, 2009.

[15] M.-M. Chren, J. S. Torres, S. E. Stuart, D. Bertenthal, R. J. Labrador, and W. J. Boscardin, "Recurrence after treatment of nonmelanoma skin cancer: a prospective cohort study," Archives of Dermatology, vol. 147, no. 5, pp. 540-546, 2011.

[16] V. Samarasinghe and V. Madan, "Nonmelanoma skin cancer," Journal of Cutaneous and Aesthetic Surgery, vol. 5, no. 1, pp. 310, 2012.

[17] NICE, Melanoma: Assessment and Management/Guidance and Guidelines, NICE-The National Institute for Health and Care Excellence, London, UK, 2015.

[18] S. Karjalainen, H. Salo, and L. Teppo, "Basal cell and squamous cell carcinoma of the skin in Finland," International Journal of Dermatology, vol. 28, no. 7, pp. 445-450, 1989.

[19] D. Czarnecki, C. Meehan, T. O’Brien, S. Leahy, and C. Nash, "The changing face of skin cancer in Australia," International Journal of Dermatology, vol. 30, no. 10, pp. 715-717, 1991.

[20] J. R. Allison Jr., "Radiation-induced basal-cell carcinoma," The Journal of Dermatologic Surgery and Oncology, vol. 10, no. 3, pp. 200-205, 1984.

[21] J. B. Howell, "Nevoid basal cell carcinoma syndrome. Profile of genetic and environmental factors in oncogenesis," Journal of the American Academy of Dermatology, vol. 11, no. 1, pp. 98-104, 1984.

[22] T. J. Wieman, E. H. Shively, and T. M. Woodcock, "Responsiveness of metastatic basal-cell carcinoma to chemotherapy. A case report," Cancer, vol. 52, no. 9, pp. 1583-1585, 1983.

[23] N. R. Rowell, "A follow-up study of superficial radiotherapy for benign dermatoses: recommendations for the use of X-rays in dermatology," British Journal of Dermatology, vol. 88, no. 6, pp. 583-590, 1973 .

[24] R. Accardi and T. Gheit, "Cutaneous HPV and skin cancer," La Presse Médicale, vol. 43, no. 12, part 2, pp. e435-e443, 2014. 
[25] B. Bridges, "Sunlight, DNA damage and skin cancer: a new perspective," Japanese Journal of Cancer Research, vol. 81, no. 2, pp. 105-107, 1990.

[26] K. H. Kraemer, M. M. Lee, and J. Scotto, "Xeroderma pigmentosum: cutaneous, ocular, and neurologic abnormalities in 830 published cases," Archives of Dermatology, vol. 123, no. 2, pp. 241-250, 1987.

[27] J. D. Brewer, O. R. Colegio, P. K. Phillips et al., "Incidence of and risk factors for skin cancer after heart transplant," Archives of Dermatology, vol. 145, no. 12, pp. 1391-1396, 2009.

[28] M. J. Silverberg, W. Leyden, E. M. Warton, C. P. Quesenberry Jr., E. A. Engels, and M. M. Asgari, "HIV infection status, immunodeficiency, and the incidence of non-melanoma skin cancer," Journal of the National Cancer Institute, vol. 105, no. 5, pp. 350-360, 2013.

[29] C. A. Harwood, T. Surentheran, P. Sasieni et al., "Increased risk of skin cancer associated with the presence of epidermodysplasia verruciformis human papillomavirus types in normal skin," British Journal of Dermatology, vol. 150, no. 5, pp. 949-957, 2004.

[30] A. Engel, M.-L. Johnson, and S. G. Haynes, "Health effects of sunlight exposure in the United States: results from the first national health and nutrition examination survey, 1971-1974," Archives of Dermatology, vol. 124, no. 1, pp. 72-79, 1988.

[31] R. Marks, G. Rennie, and T. Selwood, "Malignant transformation of solar keratoses to squamous cell carcinoma," The Lancet, vol. 331, no. 8589, pp. 795-797, 1988.

[32] B. K. Armstrong and C. D. J. Holman, "Malignant melanoma of the skin," Bulletin of the World Health Organization, vol. 65, no. 2, pp. 245-252, 1987.

[33] C. D. J. Holman and B. K. Armstrong, "Cutaneous malignant melanoma and indicators of total accumulated exposure to the sun: an analysis separating histogenetic types," Journal of the National Cancer Institute, vol. 73, no. 1, pp. 75-82, 1984.

[34] D. G. Coit, R. Andtbacka, C. J. Anker et al., "Melanoma," Journal of the National Comprehensive Cancer Network, vol.10, no. 3, pp. 366-400, 2012.

[35] P. Huang, X.-D. Yang, S.-D. Chen, and Q. Xiao, "The association between Parkinson's disease and melanoma: a systematic review and meta-analysis," Translational Neurodegeneration, vol. 4, article 21, 2015.

[36] A. Breslow, "Thickness, cross-sectional areas and depth of invasion in the prognosis of cutaneous melanoma," Annals of Surgery, vol. 172, no. 5, pp. 902-908, 1970.

[37] R. Dummer, A. Hauschild, N. Lindenblatt, G. Pentheroudakis, and U. Keilholz, "Cutaneous melanoma: ESMO Clinical Practice Guidelines for diagnosis, treatment and follow-up," Annals of Oncology, vol. 26, supplement 5, pp. v126-v132, 2015.

[38] A. Sekulic, M. R. Migden, A. E. Oro et al., "Efficacy and safety of vismodegib in advanced basal-cell carcinoma," New England Journal of Medicine, vol. 366, no. 23, pp. 2171-2179, 2012.

[39] B. P. Singh and A. K. S. Salama, "Updates in therapy for advanced melanoma," Cancers, vol. 8, no. 1, article 17, 2016.

[40] R. D. Carvajal, C. R. Antonescu, J. D. Wolchok et al., "KIT as a therapeutic target in metastatic melanoma," The Journal of the American Medical Association, vol. 305, no. 22, pp. 2327-2334, 2011.

[41] R. D. Carvajal, D. P. Lawrence, J. S. Weber et al., "Phase II study of nilotinib in melanoma harboring KIT alterations following progression to prior KIT inhibition," Clinical Cancer Research, vol. 21, no. 10, pp. 2289-2296, 2015.
[42] A. Millet, A. R. Martin, C. Ronco, S. Rocchi, and R. Benhida, "Metastatic melanoma: insights into the evolution of the treatments and future challenges," Medicinal Research Reviews, vol. 37, no. 1, pp. 98-148, 2017.

[43] F. S. Hodi, S. J. O’Day, D. F. McDermott et al., "Improved survival with ipilimumab in patients with metastatic melanoma," The New England Journal of Medicine, vol. 363, no. 8, pp. 711723, 2010.

[44] Cancer Research UK, Skin Cancer Prevention, Cancer Research UK, 2015.

[45] C. Dianzani, G. P. Zara, G. Maina et al., "Drug delivery nanoparticles in skin cancers," BioMed Research International, vol. 2014, Article ID 895986, 13 pages, 2014.

[46] L. S. Wang, M. C. Chuang, and J. A. Ho, "Nanotheranosticsa review of recent publications," International Journal of Nanomedicine, vol. 7, pp. 4679-4695, 2012.

[47] J. Xie, S. Lee, and X. Chen, "Nanoparticle-based theranostic agents," Advanced Drug Delivery Reviews, vol. 62, no. 11, pp. 1064-1079, 2010.

[48] J. Safari and Z. Zarnegar, "Advanced drug delivery systems: nanotechnology of health design A review," Journal of Saudi Chemical Society, vol. 18, no. 2, pp. 85-99, 2014.

[49] D. H. Nguyen, J. S. Lee, J. H. Choi, K. M. Park, Y. Lee, and K. D. Park, "Hierarchical self-assembly of magnetic nanoclusters for theranostics: tunable size, enhanced magnetic resonance imagability, and controlled and targeted drug delivery," Acta Biomaterialia, vol. 35, pp. 109-117, 2016.

[50] Q. Chen, X. Wang, C. Wang, L. Feng, Y. Li, and Z. Liu, "Drug-induced self-assembly of modified albumins as nanotheranostics for tumor-targeted combination therapy," ACS Nano, vol. 9, no. 5, pp. 5223-5233, 2015.

[51] J. Wu, L. Zhao, X. Xu et al., "Hydrophobic cysteine poly(disulfide)-based redox-hypersensitive nanoparticle platform for cancer theranostics," Angewandte Chemie-International Edition, vol. 54, no. 32, pp. 9218-9223, 2015.

[52] H. Maeda, K. Greish, and J. Fang, "The EPR effect and polymeric drugs: a paradigm shift for cancer chemotherapy in the 21st century," in Polymer Therapeutics II, R. Satchi-Fainaro and R. Duncan, Eds., pp. 103-121, Springer, Berlin, Germany, 2006.

[53] U. Prabhakar, H. Maeda, R. K. Jain et al., "Challenges and key considerations of the enhanced permeability and retention effect for nanomedicine drug delivery in oncology," Cancer Research, vol. 73, no. 8, pp. 2412-2417, 2013.

[54] Y. Hao, L. Wang, B. Zhang et al., "Multifunctional nanosheets based on folic acid modified manganese oxide for tumortargeting theranostic application," Nanotechnology, vol. 27, no. 2, Article ID 025101, 2016.

[55] H. Ma, Y. Liu, M. Shi et al., “Theranostic, pH-responsive, doxorubicin-loaded nanoparticles inducing active targeting and apoptosis for advanced gastric cancer," Biomacromolecules, vol. 16, no. 12, pp. 4022-4031, 2015.

[56] S. S. Kelkar and T. M. Reineke, "Theranostics: combining imaging and therapy," Bioconjugate Chemistry, vol. 22, no. 10, pp. 1879-1903, 2011.

[57] H. Ding and F. Wu, "Image guided biodistribution and pharmacokinetic studies of theranostics," Theranostics, vol. 2, no. 11, pp. 1040-1053, 2012.

[58] W. Xiao, X. Zeng, H. Lin, K. Han, H.-Z. Jia, and X.-Z. Zhang, "Dual stimuli-responsive multi-drug delivery system for the individually controlled release of anti-cancer drugs," Chemical Communications, vol. 51, no. 8, pp. 1475-1478, 2015. 
[59] K.-N. Yang, C.-Q. Zhang, W. Wang, P. C. Wang, J.-P. Zhou, and X.-J. Liang, "pH-responsive mesoporous silica nanoparticles employed in controlled drug delivery systems for cancer treatment," Cancer Biology and Medicine, vol. 11, no. 1, pp. 34-43, 2014.

[60] R. Jeetah, A. Bhaw-Luximon, and D. Jhurry, "Nanopharmaceutics: phytochemical-based controlled or sustained drugdelivery systems for cancer treatment," Journal of Biomedical Nanotechnology, vol. 10, no. 9, pp. 1810-1840, 2014.

[61] Y. Qin, J. Chen, Y. Bi et al., "Near-infrared light remote-controlled intracellular anti-cancer drug delivery using thermo/pH sensitive nanovehicle," Acta Biomaterialia, vol. 17, pp. 201-209, 2015.

[62] I. A. Khawar, J. H. Kim, and H.-J. Kuh, "Improving drug delivery to solid tumors: priming the tumor microenvironment," Journal of Controlled Release, vol. 201, pp. 78-89, 2015.

[63] M. Sefidgar, M. Soltani, K. Raahemifar, H. Bazmara, S. M. M. Nayinian, and M. Bazargan, "Effect of tumor shape, size, and tissue transport properties on drug delivery to solid tumors," Journal of Biological Engineering, vol. 8, no. 1, article no. 12, 2014.

[64] S. Kim, K. Bell, S. A. Mousa, and J. A. Varner, "Regulation of angiogenesis in vivo by ligation of integrin $\alpha 5 \beta 1$ with the central cell-binding domain of fibronectin," The American Journal of Pathology, vol. 156, no. 4, pp. 1345-1362, 2000.

[65] B. St Croix, C. Rago, V. Velculescu et al., "Genes expressed in human tumor endothelium," Science, vol. 289, no. 5482, pp. 1197-1202, 2000.

[66] D. F. Emerich and C. G. Thanos, “Targeted nanoparticle-based drug delivery and diagnosis," Journal of Drug Targeting, vol. 15, no. 3, pp. 163-183, 2007.

[67] W. Arap, R. Pasqualini, and E. Ruoslahti, "Cancer treatment by targeted drug delivery to tumor vasculature in a mouse model," Science, vol. 279, no. 5349, pp. 377-380, 1998.

[68] M. P. Turunen, H. L. Puhakka, J. K. Koponen et al., "Peptideretargeted adenovirus encoding a tissue inhibitor of metalloproteinase- 1 decreases restenosis after intravascular gene transfer," Molecular Therapy, vol. 6, no. 3, pp. 306-312, 2002.

[69] F. Curnis, A. Sacchi, and A. Corti, "Improving chemotherapeutic drug penetration in tumors by vascular targeting and barrier alteration," The Journal of Clinical Investigation, vol. 110, no. 4, pp. 475-482, 2002.

[70] J. D. Hood, M. Bednarski, R. Frausto et al., "Tumor regression by targeted gene delivery to the neovasculature," Science, vol. 296, no. 5577, pp. 2404-2407, 2002.

[71] P. M. Winter, S. D. Caruthers, A. Kassner et al., "Molecular imaging of angiogenesis in nascent $\mathrm{Vx}-2$ rabbit tumors using a novel $\alpha \mathrm{v} \beta 3$-targeted nanoparticle and 1.5 Tesla magnetic resonance imaging," Cancer Research, vol. 63, no. 18, pp. 58385843, 2003.

[72] M. E. Åkerman, W. C. W. Chan, P. Laakkonen, S. N. Bhatia, and E. Ruoslahti, "Nanocrystal targeting in vivo," Proceedings of the National Academy of Sciences of the United States of America, vol. 99, no. 20, pp. 12617-12621, 2002.

[73] F. Pastorino, C. Brignole, D. Marimpietri et al., "Vascular damage and anti-angiogenic effects of tumor vessel-targeted liposomal chemotherapy," Cancer Research, vol. 63, no. 21, pp. 7400-7409, 2003.

[74] M. Christofidou-Solomidou, G. G. Pietra, C. C. Solomides et al., "Immunotargeting of glucose oxidase to endothelium in vivo causes oxidative vascular injury in the lungs," American Journal of Physiology, vol. 278, no. 4, pp. L794-L805, 2000.
[75] S. Yu, C. He, Q. Lv et al., "pH and reduction-sensitive disulfide cross-linked polyurethane micelles for bio-triggered anti-tumor drug delivery," Journal of Controlled Release, vol. 213, pp. e99e100, 2015.

[76] K. Sanka, R. R. Pragada, and P. R. Veerareddy, "A pH-triggered delayed-release chronotherapeutic drug delivery system of aceclofenac for effective management of early morning symptoms of rheumatoid arthritis," Journal of Microencapsulation, vol. 32, no. 8, pp. 794-803, 2015.

[77] Z. Yuan, Z. Que, S. Cheng, R. Zhuo, and F. Li, "PH-triggered blooming of 'nano-flowers' for tumor intracellular drug delivery," Chemical Communications, vol. 48, no. 65, pp. 8129-8131, 2012.

[78] A. Guha, N. Biswas, K. Bhattacharjee, P. Das, and K. Kuotsu, "In vitro evaluation of $\mathrm{pH}$ responsive Doxazosin loaded mesoporous silica nanoparticles: a smart approach in drug delivery," Current Drug Delivery, vol. 13, no. 4, pp. 574-581, 2016.

[79] Y. Chen, K. Ai, J. Liu, G. Sun, Q. Yin, and L. Lu, "Multifunctional envelope-type mesoporous silica nanoparticles for $\mathrm{pH}$ responsive drug delivery and magnetic resonance imaging," Biomaterials, vol. 60, pp. 111-120, 2015.

[80] C. de la Torre, A. Agostini, L. Mondragón et al., “Temperaturecontrolled release by changes in the secondary structure of peptides anchored onto mesoporous silica supports," Chemical Communications, vol. 50, no. 24, pp. 3184-3186, 2014.

[81] Y. Jiao, Y. Sun, B. Chang, D. Lu, and W. Yang, "Redox- and temperature-controlled drug release from hollow mesoporous silica nanoparticles," Chemistry, vol. 19, no. 45, pp. 15410-15420, 2013.

[82] J. Dong and J. I. Zink, "Simultaneous spectroscopic measurements of the interior temperature and induced cargo release from pore-restricted mesoporous silica nanoparticles," Nanoscale, vol. 8, no. 20, pp. 10558-10563, 2016.

[83] E. Aznar, L. Mondragõn, J. V. Ros-Lis et al., "Finely tuned temperature-controlled cargo release using paraffin-capped mesoporous silica nanoparticles," Angewandte Chemie-nternational Edition, vol. 50, no. 47, pp. 11172-11175, 2011.

[84] T. K. Jain, M. A. Morales, S. K. Sahoo, D. L. Leslie-Pelecky, and V. Labhasetwar, "Iron oxide nanoparticles for sustained delivery of anticancer agents," Molecular Pharmaceutics, vol. 2, no. 3, pp. 194-205, 2005.

[85] K. Murakami, X. Yu, S. Watanabe, T. Kato, Y. Inoue, and K. Sugawara, "Synthesis of thermosensitive polymer/mesoporous silica composite and its temperature dependence of anion exchange property," Journal of Colloid and Interface Science, vol. 354, no. 2, pp. 771-776, 2011.

[86] M. Colilla, B. González, and M. Vallet-Regí, "Mesoporous silica nanoparticles for the design of smart delivery nanodevices," Biomaterials Science, vol. 1, no. 2, pp. 114-134, 2013.

[87] A. Zintchenko, M. Ogris, and E. Wagner, “Temperature dependent gene expression induced by PNIPAM-based copolymers: potential of hyperthermia in gene transfer," Bioconjugate Chemistry, vol. 17, no. 3, pp. 766-772, 2006.

[88] K. Nagase, J. Kobayashi, A. Kikuchi, Y. Akiyama, H. Kanazawa, and T. Okano, "Interfacial property modulation of thermoresponsive polymer brush surfaces and their interaction with biomolecules," Langmuir, vol. 23, no. 18, pp. 9409-9415, 2007.

[89] M. Keerl, V. Smirnovas, R. Winter, and W. Richtering, "Copolymer microgels from mono- and disubstituted acrylamides: phase behavior and hydrogen bonds," Macromolecules, vol. 41, no. 18, pp. 6830-6836, 2008. 
[90] T. Hoare, J. Santamaria, G. F. Goya et al., "A magnetically triggered composite membrane for on-demand drug delivery," Nano Letters, vol. 9, no. 10, pp. 3651-3657, 2009.

[91] S. Baek, R. K. Singh, D. Khanal et al., "Smart multifunctional drug delivery towards anticancer therapy harmonized in mesoporous nanoparticles," Nanoscale, vol. 7, no. 34, pp. 14191-14216, 2015.

[92] C.-Y. Lai, B. G. Trewyn, D. M. Jeftinija et al., "A mesoporous silica nanosphere-based carrier system with chemically removable CdS nanoparticle caps for stimuli-responsive controlled release of neurotransmitters and drug molecules," Journal of the American Chemical Society, vol. 125, no. 15, pp. 4451-4459, 2003.

[93] S. Giri, B. G. Trewyn, M. P. Stellmaker, and V. S.-Y. Lin, "Stimuliresponsive controlled-release delivery system based on mesoporous silica nanorods capped with magnetic nanoparticles," Angewandte Chemie - International Edition, vol. 44, no. 32, pp. 5038-5044, 2005.

[94] F. Torney, B. G. Trewyn, V. S.-Y. Lin, and K. Wang, "Mesoporous silica nanoparticles deliver DNA and chemicals into plants," Nature Nanotechnology, vol. 2, no. 5, pp. 295-300, 2007.

[95] P. Nadrah, U. Maver, A. Jemec et al., "Hindered disulfide bonds to regulate release rate of model drug from mesoporous silica," ACS Applied Materials and Interfaces, vol. 5, no. 9, pp. 39083915, 2013.

[96] A. Bernardos, E. Aznar, M. D. Marcos et al., "Enzyme-responsive controlled release using mesoporous silica supports capped with lactose," Angewandte Chemie-International Edition, vol. 48, no. 32, pp. 5884-5887, 2009.

[97] E. Climent, A. Bernardos, R. Martínez-Máñez et al., “Controlled delivery systems using antibody-capped mesoporous nanocontainers," Journal of the American Chemical Society, vol. 131, no. 39, pp. 14075-14080, 2009.

[98] B. Sahoo, K. S. P. Devi, S. Dutta, T. K. Maiti, P. Pramanik, and D. Dhara, "Biocompatible mesoporous silica-coated superparamagnetic manganese ferrite nanoparticles for targeted drug delivery and MR imaging applications," Journal of Colloid and Interface Science, vol. 431, pp. 31-41, 2014.

[99] G. R. Bardajee and Z. Hooshyar, "One-pot synthesis of biocompatible superparamagnetic iron oxide nanoparticles/hydrogel based on salep: characterization and drug delivery," Carbohydrate Polymers, vol. 101, no. 1, pp. 741-751, 2014.

[100] U. Maver, M. Bele, D. Makovec, S. Čampelj, J. Jamnik, and M. Gaberšček, "Incorporation and release of drug into/from superparamagnetic iron oxide nanoparticles," Journal of Magnetism and Magnetic Materials, vol. 321, no. 19, pp. 3187-3192, 2009.

[101] D. Makovec, S. Čampelj, M. Bele et al., "Nanocomposites containing embedded superparamagnetic iron oxide nanoparticles and rhodamine 6G," Colloids and Surfaces A: Physicochemical and Engineering Aspects, vol. 334, no. 1-3, pp. 74-79, 2009.

[102] M. Talelli, C. J. F. Rijcken, T. Lammers et al., "Superparamagnetic iron oxide nanoparticles encapsulated in biodegradable thermosensitive polymeric micelles: toward a targeted nanomedicine suitable for image-guided drug delivery," Langmuir, vol. 25, no. 4, pp. 2060-2067, 2009.

[103] L. Liu, P. Yu, Y. Zhang et al., "Doxorubicin-conjugated magnetic iron oxide nanoparticles for $\mathrm{pH}$-sensitive and magnetic responsive drug delivery," Journal of Controlled Release, vol. 213, article e67, 2015.

[104] A. R. K. Sasikala, A. GhavamiNejad, A. R. Unnithan et al., "A smart magnetic nanoplatform for synergistic anticancer therapy: manoeuvring mussel-inspired functional magnetic nanoparticles for $\mathrm{pH}$ responsive anticancer drug delivery and hyperthermia," Nanoscale, vol. 7, no. 43, pp. 18119-18128, 2015.

[105] H. Kakwere, M. P. Leal, M. E. Materia et al., "Functionalization of strongly interacting magnetic nanocubes with (thermo)responsive coating and their application in hyperthermia and heat-triggered drug delivery," ACS Applied Materials and Interfaces, vol. 7, no. 19, pp. 10132-10145, 2015.

[106] D. E. Owens III and N. A. Peppas, "Opsonization, biodistribution, and pharmacokinetics of polymeric nanoparticles," International Journal of Pharmaceutics, vol. 307, no. 1, pp. 93102, 2006.

[107] I. A. Alvi, J. Madan, D. Kaushik, S. Sardana, R. S. Pandey, and A. Ali, "Comparative study of transfersomes, liposomes, and niosomes for topical delivery of 5-fluorouracil to skin cancer cells: preparation, characterization, in-vitro release, and cytotoxicity analysis," Anti-Cancer Drugs, vol. 22, no. 8, pp. 774-782, 2011.

[108] A. Bunker, A. Magarkar, and T. Viitala, "Rational design of liposomal drug delivery systems, a review: combined experimental and computational studies of lipid membranes, liposomes and their PEGylation," Biochimica et Biophysica Acta (BBA)Biomembranes, vol. 1858, no. 10, pp. 2334-2352, 2016.

[109] M. Dorrani, O. B. Garbuzenko, T. Minko, and B. MichniakKohn, "Development of edge-activated liposomes for siRNA delivery to human basal epidermis for melanoma therapy," Journal of Controlled Release, vol. 228, pp. 150-158, 2016.

[110] K. Shi, J. Li, Z. Cao et al., "A pH-responsive cell-penetrating peptide-modified liposomes with active recognizing of integrin alphavbeta3 for the treatment of melanoma," Journal of Controlled Release, vol. 217, pp. 138-150, 2015.

[111] Z. Chen, T. Zhang, B. Wu, and X. Zhang, "Insights into the therapeutic potential of hypoxia-inducible factor- $1 \alpha$ small interfering RNA in malignant melanoma delivered via folate-decorated cationic liposomes," International Journal of Nanomedicine, vol. 11, pp. 991-1002, 2016.

[112] Y.-P. Fang, Y.-H. Tsai, P.-C. Wu, and Y.-B. Huang, "Comparison of 5-aminolevulinic acid-encapsulated liposome versus ethosome for skin delivery for photodynamic therapy," International Journal of Pharmaceutics, vol. 356, no. 1-2, pp. 144-152, 2008.

[113] T. Geetha, M. Kapila, O. Prakash, P. K. Deol, V. Kakkar, and I. P. Kaur, "Sesamol-loaded solid lipid nanoparticles for treatment of skin cancer," Journal of Drug Targeting, vol. 23, no. 2, pp. 159169, 2015.

[114] M. B. de Jesus, C. V. Ferreira, E. de Paula, D. Hoekstra, and I. S. Zuhorn, "Design of solid lipid nanoparticles for gene delivery into prostate cancer," Journal of Controlled Release, vol. 148, no. 1, pp. e89-e90, 2010.

[115] M. Sasidharan and K. Nakashima, "Core-shell-corona polymeric micelles as a versatile template for synthesis of inorganic hollow nanospheres," Accounts of Chemical Research, vol. 47, no. 1, pp. 157-167, 2014.

[116] A. E. Felber, M.-H. Dufresne, and J.-C. Leroux, "PH-sensitive vesicles, polymeric micelles, and nanospheres prepared with polycarboxylates," Advanced Drug Delivery Reviews, vol. 64, no. 11, pp. 979-992, 2012.

[117] B. P. K. Reddy, H. K. S. Yadav, D. K. Nagesha, A. Raizaday, and A. Karim, "Polymeric micelles as novel carriers for poorly soluble drugs-a review," Journal of Nanoscience and Nanotechnology, vol. 15, no. 6, pp. 4009-4018, 2015.

[118] K. Letchford and H. Burt, "A review of the formation and classification of amphiphilic block copolymer nanoparticulate structures: micelles, nanospheres, nanocapsules and polymersomes," 
European Journal of Pharmaceutics and Biopharmaceutics, vol. 65, no. 3, pp. 259-269, 2007.

[119] P. Mi, N. Dewi, H. Yanagie et al., "Hybrid calcium phosphatepolymeric micelles incorporating gadolinium chelates for imaging-guided gadolinium neutron capture tumor therapy," ACS Nano, vol. 9, no. 6, pp. 5913-5921, 2015.

[120] Y. Heta, K. Kumaki, H. Hifumi, D. Citterio, A. Tanimoto, and K. Suzuki, "Gadolinium containing photochromic micelles as potential magnetic resonance imaging traceable drug carriers," Photochemistry and Photobiology, vol. 88, no. 4, pp. 876-883, 2012.

[121] I. Singh, A. K. Rehni, R. Kalra, G. Joshi, and M. Kumar, "Dendrimers and their pharmaceutical applications-a review," Pharmazie, vol. 63, no. 7, pp. 491-496, 2008.

[122] A. Agarwal, A. Asthana, U. Gupta, and N. K. Jain, "Tumour and dendrimers: a review on drug delivery aspects," Journal of Pharmacy and Pharmacology, vol. 60, no. 6, pp. 671-688, 2008.

[123] D. J. Bharali, M. Khalil, M. Gurbuz, T. M. Simone, and S. A. Mousa, "Nanoparticles and cancer therapy: a concise review with emphasis on dendrimers," International Journal of Nanomedicine, vol. 4, no. 1, pp. 1-7, 2009.

[124] J. Yan, W. Li, and A. Zhang, "Dendronized supramolecular polymers," Chemical Communications, vol. 50, no. 82, pp. 1222112233, 2014.

[125] M. Kumari, S. Gupta, K. Achazi et al., "Dendronized multifunctional amphiphilic polymers as efficient nanocarriers for biomedical applications," Macromolecular Rapid Communications, vol. 36, no. 2, pp. 254-261, 2015.

[126] E. Córdova-Mateo, O. Bertran, B. Zhang et al., "Interactions in dendronized polymers: intramolecular dominates intermolecular," Soft Matter, vol. 10, no. 7, pp. 1032-1044, 2014.

[127] J. Yan, W. Li, K. Liu et al., "Thermoresponsive supramolecular dendronized polymers," Chemistry, vol. 6, no. 12, pp. 3260-3269, 2011.

[128] F. Liang and B. Chen, "A review on biomedical applications of single-walled carbon nanotubes," Current Medicinal Chemistry, vol. 17, no. 1, pp. 10-24, 2010.

[129] J.-P. Tessonnier and D. S. Su, "Recent progress on the growth mechanism of carbon nanotubes: a review," ChemSusChem, vol. 4, no. 7, pp. 824-847, 2011.

[130] Z. Zhu, L. Garcia-Gancedo, A. J. Flewitt, H. Xie, F. Moussy, and W. I. Milne, "A critical review of glucose biosensors based on carbon nanomaterials: carbon nanotubes and graphene," Sensors, vol. 12, no. 5, pp. 5996-6022, 2012.

[131] D. Vairavapandian, P. Vichchulada, and M. D. Lay, "Preparation and modification of carbon nanotubes: review of recent advances and applications in catalysis and sensing," Analytica Chimica Acta, vol. 626, no. 2, pp. 119-129, 2008.

[132] B. Dineshkumar, K. Krishnakumar, A. R. Bhatt et al., "Singlewalled and multi-walled carbon nanotubes based drug delivery system: cancer therapy: a review," Indian Journal of Cancer, vol. 52, no. 3, pp. 262-264, 2015.

[133] G. Cirillo, S. Hampel, U. G. Spizzirri, O. I. Parisi, N. Picci, and F. Iemma, "Carbon nanotubes hybrid hydrogels in drug delivery: a perspective review," BioMed Research International, vol. 2014, Article ID 825017, 17 pages, 2014.

[134] T. Ukmar, U. Maver, O. Planinšek, V. Kaučič, M. Gaberšček, and A. Godec, "Understanding controlled drug release from mesoporous silicates: theory and experiment," Journal of Controlled Release, vol. 155, no. 3, pp. 409-417, 2011.
[135] A. Godec, U. Maver, M. Bele et al., "Vitrification from solution in restricted space: formation and stabilization of amorphous nifedipine in a nanoporous silica xerogel carrier," International Journal of Pharmaceutics, vol. 343, no. 1-2, pp. 131-140, 2007.

[136] U. Maver, A. Godec, M. Bele et al., "Novel hybrid silica xerogels for stabilization and controlled release of drug," International Journal of Pharmaceutics, vol. 330, no. 1-2, pp. 164-174, 2007.

[137] S. Ghaderi, B. Ramesh, and A. M. Seifalian, "Fluorescence nanoparticles "quantum dots" as drug delivery system and their toxicity: a review," Journal of Drug Targeting, vol. 19, no. 7, pp. 475-486, 2011.

[138] W. R. Algar, A. J. Tavares, and U. J. Krull, "Beyond labels: a review of the application of quantum dots as integrated components of assays, bioprobes, and biosensors utilizing optical transduction," Analytica Chimica Acta, vol. 673, no. 1, pp. 1-25, 2010.

[139] E. Petryayeva, W. R. Algar, and I. L. Medintz, "Quantum dots in bioanalysis: a review of applications across various platforms for fluorescence spectroscopy and imaging," Applied Spectroscopy, vol. 67, no. 3, pp. 215-252, 2013.

[140] A. Tan, L. Yildirimer, J. Rajadas, H. De La Peña, G. Pastorin, and A. Seifalian, "Quantum dots and carbon nanotubes in oncology: a review on emerging theranostic applications in nanomedicine," Nanomedicine, vol. 6, no. 6, pp. 1101-1114, 2011.

[141] M. J. Kim, J. Y. Lee, U. Nehrbass, R. Song, and Y. Choi, “Detection of melanoma using antibody-conjugated quantum dots in a coculture model for high-throughput screening system," Analyst, vol. 137, no. 6, pp. 1440-1445, 2012.

[142] S. Steponkiene, S. Kavaliauskiene, R. Purviniene, R. Rotomskis, and P. Juzenas, "Quantum dots affect expression of CD133 surface antigen in melanoma cells," International Journal of Nanomedicine, vol. 6, pp. 2437-2444, 2011.

[143] M. Singh, D. C. C. Harris-Birtill, S. R. Markar, G. B. Hanna, and D. S. Elson, "Application of gold nanoparticles for gastrointestinal cancer theranostics: a systematic review," Nanomedicine: Nanotechnology, Biology, and Medicine, vol. 11, no. 8, pp. 20832098, 2015.

[144] M. R. K. Ali, S. R. Panikkanvalappil, and M. A. El-Sayed, "Enhancing the efficiency of gold nanoparticles treatment of cancer by increasing their rate of endocytosis and cell accumulation using rifampicin," Journal of the American Chemical Society, vol. 136, no. 12, pp. 4464-4467, 2014.

[145] A. Kumar, H. Ma, X. Zhang et al., "Gold nanoparticles functionalized with therapeutic and targeted peptides for cancer treatment," Biomaterials, vol. 33, no. 4, pp. 1180-1189, 2012.

[146] J. Lee, D. K. Chatterjee, M. H. Lee, and S. Krishnan, "Gold nanoparticles in breast cancer treatment: promise and potential pitfalls," Cancer Letters, vol. 347, no. 1, pp. 46-53, 2014.

[147] E. C. Dreaden, B. E. Gryder, L. A. Austin et al., "Antiandrogen gold nanoparticles dual-target and overcome treatment resistance in hormone-insensitive prostate cancer cells," Bioconjugate Chemistry, vol. 23, no. 8, pp. 1507-1512, 2012.

[148] M. L. Mojica Pisciotti, E. Lima Jr., M. Vasquez Mansilla et al., "In vitro and in vivo experiments with iron oxide nanoparticles functionalized with DEXTRAN or polyethylene glycol for medical applications: magnetic targeting," Journal of Biomedical Materials Research Part B: Applied Biomaterials, vol. 102, no. 4, pp. 860-868, 2014.

[149] Y. Mi, X. Liu, J. Zhao, J. Ding, and S.-S. Feng, "Multimodality treatment of cancer with herceptin conjugated, thermomagnetic iron oxides and docetaxel loaded nanoparticles of 
biodegradable polymers," Biomaterials, vol. 33, no. 30, pp. 75197529, 2012.

[150] X. He, F. Liu, L. Liu, T. Duan, H. Zhang, and Z. Wang, "Lectinconjugated Fe2O3@Au core@shell nanoparticles as dual mode contrast agents for in vivo detection of tumor," Molecular Pharmaceutics, vol. 11, no. 3, pp. 738-745, 2014.

[151] H. Basti, L. Ben Tahar, L. S. Smiri et al., "Catechol derivativescoated $\mathrm{Fe}_{3} \mathrm{O}_{4}$ and $\gamma-\mathrm{Fe}_{2} \mathrm{O}_{3}$ nanoparticles as potential MRI contrast agents," Journal of Colloid and Interface Science, vol. 341, no. 2, pp. 248-254, 2010.

[152] Z.-Y. Wang, J. Song, and D.-S. Zhang, "Nanosized $\mathrm{As}_{2} \mathrm{O}_{3} / \mathrm{Fe}_{2} \mathrm{O}_{3}$ complexes combined with magnetic fluid hyperthermia selectively target liver cancer cells," World Journal of Gastroenterology, vol. 15, no. 24, pp. 2995-3002, 2009.

[153] J. Zhou, J. Li, X. Ding et al., "Multifunctional Fe2O3@PPyPEG nanocomposite for combination cancer therapy with MR imaging," Nanotechnology, vol. 26, no. 42, p. 425101, 2015.

[154] Y.-H. Ma, H.-Y. Peng, R.-X. Yang, and F. Ni, "Preparation of lysine-coated magnetic fe2o3 nanoparticles and influence on viability of a549 lung cancer cells," Asian Pacific Journal of Cancer Prevention, vol. 15, no. 20, pp. 8981-8985, 2014.

[155] S. Y. Yan, M. M. Chen, J. G. Fan et al., “Therapeutic mechanism of treating smmc-7721 liver cancer cells with magnetic fluid hyperthermia using $\mathrm{Fe} 2 \mathrm{O} 3$ nanoparticles," Brazilian Journal of Medical and Biological Research, vol. 47, no. 11, pp. 947-959, 2014.

[156] A. B. Salunkhe, V. M. Khot, and S. H. Pawar, "Magnetic hyperthermia with magnetic nanoparticles: a status review," Current Topics in Medicinal Chemistry, vol. 14, no. 5, pp. 572594, 2014.

[157] A. J. Giustini, A. A. Petryk, S. M. Cassim, J. A. Tate, I. Baker, and P. J. Hoopes, "Magnetic nanoparticle hyperthermia in cancer treatment," Nano LIFE, vol. 01, no. 01n02, pp. 17-32, 2010.

[158] R. Hu, S. Ma, X. Ke, H. Jiang, D. Wei, and W. Wang, "Effect of interleukin-2 treatment combined with magnetic fluid hyperthermia on Lewis lung cancer-bearing mice," Biomedical Reports, vol. 4, no. 1, pp. 59-62, 2016.

[159] M. Bañobre-López, A. Teijeiro, and J. Rivas, "Magnetic nanoparticle-based hyperthermia for cancer treatment," Reports of Practical Oncology and Radiotherapy, vol. 18, no. 6, pp. 397-400, 2013.

[160] A. Espinosa, R. Di Corato, J. Kolosnjaj-Tabi, P. Flaud, T. Pellegrino, and C. Wilhelm, "Duality of iron oxide nanoparticles in cancer therapy: amplification of heating efficiency by magnetic hyperthermia and photothermal bimodal treatment," ACS Nano, vol. 10, no. 2, pp. 2436-2446, 2016.

[161] A. A. Petryk, A. J. Giustini, R. E. Gottesman, P. A. Kaufman, and P. J. Hoopes, "Magnetic nanoparticle hyperthermia enhancement of cisplatin chemotherapy cancer treatment," International Journal of Hyperthermia, vol. 29, no. 8, pp. 845851, 2013.

[162] S. K. Calderwood, M. A. Stevenson, and A. Murshid, "Heat shock proteins, autoimmunity, and cancer treatment," Autoimmune Diseases, vol. 1, no. 1, Article ID 486069, 2012.

[163] C. T. Avedisian, R. E. Cavicchi, P. L. McEuen, and X. Zhou, "Nanoparticles for cancer treatment: role of heat transfer," Annals of the New York Academy of Sciences, vol. 1161, pp. 6273, 2009.

[164] M. Kawashita, S. Domi, Y. Saito et al., "In vitro heat generation by ferrimagnetic maghemite microspheres for hyperthermic treatment of cancer under an alternating magnetic field," Journal of Materials Science: Materials in Medicine, vol. 19, no. 5, pp. 1897-1903, 2008.
[165] K. Hayashi, M. Nakamura, H. Miki et al., "Magnetically responsive smart nanoparticles for cancer treatment with a combination of magnetic hyperthermia and remote-control drug release," Theranostics, vol. 4, no. 8, pp. 834-844, 2014.

[166] J. Chen, R. Shao, X. D. Zhang, and C. Chen, "Applications of nanotechnology for melanoma treatment, diagnosis, and theranostics," International Journal of Nanomedicine, vol. 8, pp. 2677-2688, 2013.

[167] M. B. R. Pierre, A. C. Tedesco, J. M. Marchetti, and M. V. L. B. Bentley, "Stratum corneum lipids liposomes for the topical delivery of 5-aminolevulinic acid in photodynamic therapy of skin cancer: preparation and in vitro permeation study," $B M C$ Dermatology, vol. 1, article 5, 2001.

[168] A. Y. Bedikian, N. E. Papadopoulos, K. B. Kim et al., "A pilot study with vincristine sulfate liposome infusion in patients with metastatic melanoma," Melanoma Research, vol. 18, no. 6, pp. 400-404, 2008.

[169] L. A. Huber, T. A. Pereira, D. N. Ramos et al., “Topical skin cancer therapy using doxorubicin-loaded cationic lipid nanoparticles and iontophoresis," Journal of Biomedical Nanotechnology, vol. 11, no. 11, pp. 1975-1988, 2015.

[170] R. H. Wilson, R. Plummer, J. Adam et al., "Phase I and pharmacokinetic study of NC-6004, a new platinum entity of cisplatin-conjugated polymer forming micelles," Journal of Clinical Oncology, vol. 26, no. 15, supplement 1, abstract 2573, 2008, Proceedings of the ASCO Annual Meeting.

[171] H. Yang, "Targeted nanosystems: advances in targeted dendrimers for cancer therapy," Nanomedicine: Nanotechnology, Biology, and Medicine, vol. 12, no. 2, pp. 309-316, 2016.

[172] S. Somani and C. Dufès, "Applications of dendrimers for brain delivery and cancer therapy," Nanomedicine, vol. 9, no. 15, pp. 2403-2414, 2014.

[173] N. G. Sahoo, H. Bao, Y. Pan et al., "Functionalized carbon nanomaterials as nanocarriers for loading and delivery of a poorly water-soluble anticancer drug: a comparative study," Chemical Communications, vol. 47, no. 18, pp. 5235-5237, 2011.

[174] B. B. Choi, M. S. Kim, K. W. Song et al., "Targeting NEU protein in melanoma cells with non-thermal atmospheric pressure plasma and gold nanoparticles," Journal of Biomedical Nanotechnology, vol. 11, no. 5, pp. 900-905, 2015.

[175] S. Labala, P. K. Mandapalli, A. Kurumaddali, and V. V. K. Venuganti, "Layer-by-layer polymer coated gold nanoparticles for topical delivery of imatinib mesylate to treat melanoma," Molecular Pharmaceutics, vol. 12, no. 3, pp. 878-888, 2015.

[176] Y.-F. Rao, W. Chen, X.-G. Liang et al., "Epirubicin-loaded superparamagnetic iron-oxide nanoparticles for transdermal delivery: cancer therapy by circumventing the skin barrier," Small, vol. 11, no. 2, pp. 239-247, 2015.

[177] J. Funkhouser, "Reinventing pharma: the theranostic revolution," Current Drug Discovery, vol. 2, pp. 17-19, 2002.

[178] Z.-R. Lu, "Theranostics: fusion of therapeutics and diagnostics," Pharmaceutical Research, vol. 31, no. 6, pp. 1355-1357, 2014.

[179] S. Jeelani, R. C. Jagat Reddy, T. Maheswaran, G. S. Asokan, A. Dany, and B. Anand, "Theranostics: a treasured tailor for tomorrow," Journal of Pharmacy and Bioallied Sciences, vol. 6, supplement 1, pp. S6-S8, 2014.

[180] B. G. Feagan, M. Lémann, R. Befrits et al., "Recommendations for the treatment of Crohn's disease with tumor necrosis factor antagonists: an expert consensus report," Inflammatory Bowel Diseases, vol. 18, no. 1, pp. 152-160, 2012. 
[181] V. von Felbert, D. Bauerschlag, N. Maass et al., "A specific photoimmunotheranostics agent to detect and eliminate skin cancer cells expressing EGFR," Journal of Cancer Research and Clinical Oncology, vol. 142, no. 5, pp. 1003-1011, 2016.

[182] L. Vannucci, E. Falvo, M. Fornara et al., "Selective targeting of melanoma by PEG-masked protein-based multifunctional nanoparticles," International Journal of Nanomedicine, vol. 7, pp. 1489-1509, 2012.

[183] M. Ma, Y. Hao, N. Liu et al., "A novel lipid-based nanomicelle of docetaxel: Evaluation of antitumor activity and biodistribution," International Journal of Nanomedicine, vol. 7, pp. 3389-3398, 2012.

[184] R. Bazak, M. Houri, S. El Achy, S. Kamel, and T. Refaat, "Cancer active targeting by nanoparticles: a comprehensive review of literature," Journal of Cancer Research and Clinical Oncology, vol. 141, no. 5, pp. 769-784, 2015.

[185] S. Sultana, M. R. Khan, M. Kumar, S. Kumar, and M. Ali, "Nanoparticles-mediated drug delivery approaches for cancer targeting: a review," Journal of Drug Targeting, vol. 21, no. 2, pp. 107-125, 2013.

[186] H. Wang, D.-K. Lee, K.-Y. Chen et al., "Mechanismindependent optimization of combinatorial nanodiamond and unmodified drug delivery using a phenotypically driven platform technology," ACS Nano, vol. 9, no. 3, pp. 3332-3344, 2015.

[187] N. Bertrand, J. Wu, X. Xu, N. Kamaly, and O. C. Farokhzad, "Cancer nanotechnology: the impact of passive and active targeting in the era of modern cancer biology," Advanced Drug Delivery Reviews, vol. 66, pp. 2-25, 2014.

[188] F. K. dos Santos, M. H. Oyafuso, C. P. Kiill, M. P. DaflonGremião, and M. Chorilli, "Nanotechnology-based drug delivery systems for treatment of hyperproliferative skin diseases-a review," Current Nanoscience, vol. 9, no. 1, pp. 159-167, 2013.

[189] D. E. Speiser, K. Schwarz, P. Baumgaertner et al., "Memory and effector CD8 T-cell responses after nanoparticle vaccination of melanoma patients," Journal of Immunotherapy, vol. 33, no. 8, pp. 848-858, 2010.

[190] T. M. Allen and P. R. Cullis, "Liposomal drug delivery systems: from concept to clinical applications," Advanced Drug Delivery Reviews, vol. 65, no. 1, pp. 36-48, 2013.

[191] K. S. Siu, D. Chen, X. Zheng et al., "Non-covalently functionalized single-walled carbon nanotube for topical siRNA delivery into melanoma," Biomaterials, vol. 35 , no. 10, pp. 3435-3442, 2014.

[192] H. S. Jung, W. H. Kong, D. K. Sung et al., "Nanographene oxidehyaluronic acid conjugate for photothermal ablation therapy of skin cancer," ACS Nano, vol. 8, no. 1, pp. 260-268, 2014.

[193] P. Sharma, N. K. Mehra, K. Jain, and N. K. Jain, "Biomedical applications of carbon nanotubes: a critical review," Current Drug Delivery, vol. 13, no. 6, pp. 796-817, 2016.

[194] F. Navarro-Pardo, A. L. Martinez-Hernandez, and C. VelascoSantos, "Carbon nanotube and graphene based polyamide electrospun nanocomposites: a review," Journal of Nanomaterials, vol. 2016, Article ID 3182761, 16 pages, 2016.

[195] E. Amstad, M. Textor, and E. Reimhult, "Stabilization and functionalization of iron oxide nanoparticles for biomedical applications," Nanoscale, vol. 3, no. 7, pp. 2819-2843, 2011.

[196] H. Zhao, Z. Li, B. Yang, J. Wang, and Y. Li, "Synthesis of dual-functional targeting probes for cancer theranostics based on iron oxide nanoparticles coated by centipede-like polymer connected with $\mathrm{pH}$-responsive anticancer drug," Journal of
Biomaterials Science, Polymer Edition, vol. 26, no. 16, pp. 11781189, 2015.

[197] Y. Ling, K. Wei, Y. Luo, X. Gao, and S. Zhong, "Dual docetaxel/superparamagnetic iron oxide loaded nanoparticles for both targeting magnetic resonance imaging and cancer therapy," Biomaterials, vol. 32, no. 29, pp. 7139-7150, 2011. 

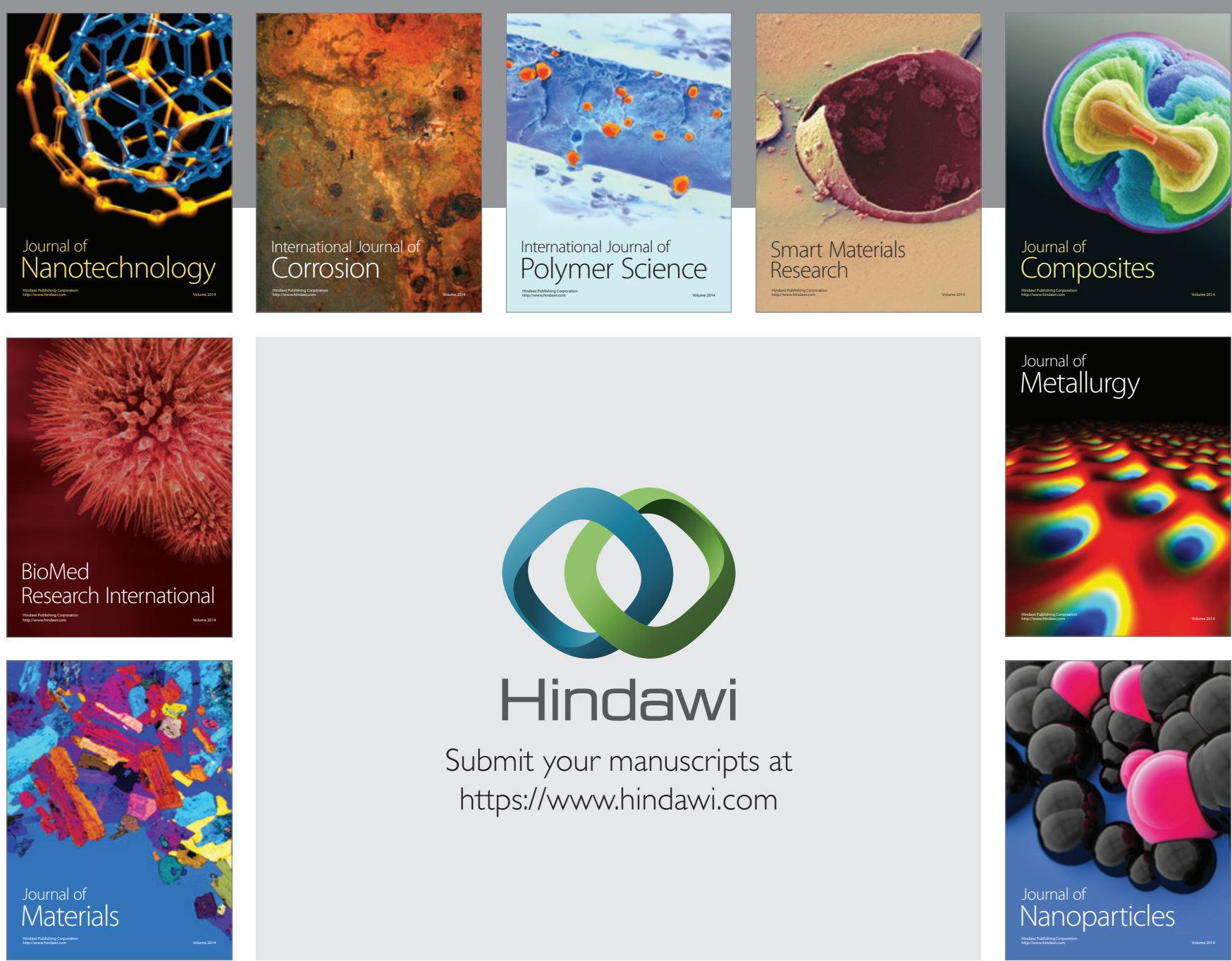

\section{Hindawi}

Submit your manuscripts at

https://www.hindawi.com

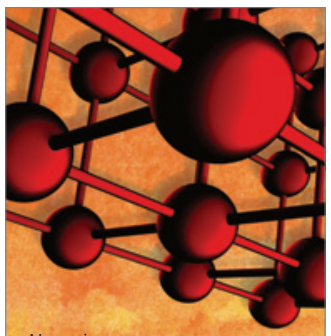

Materials Science and Engineering
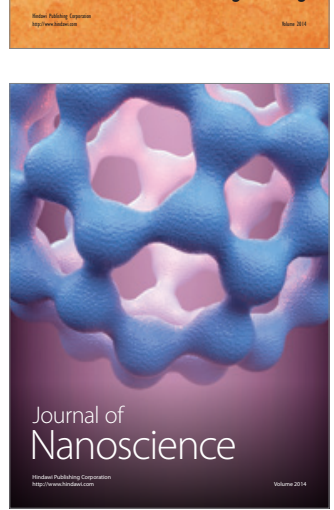
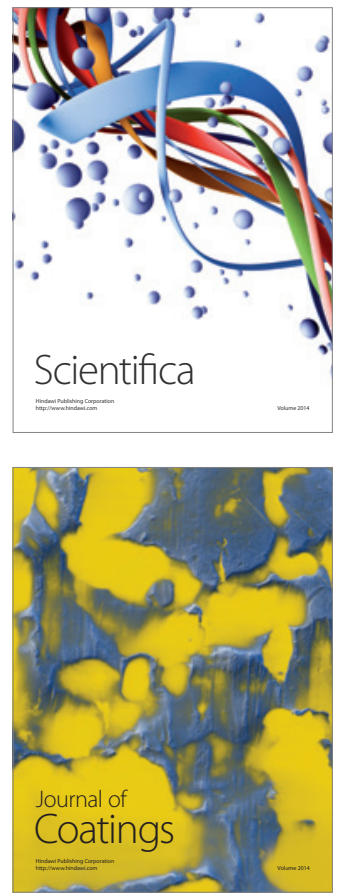
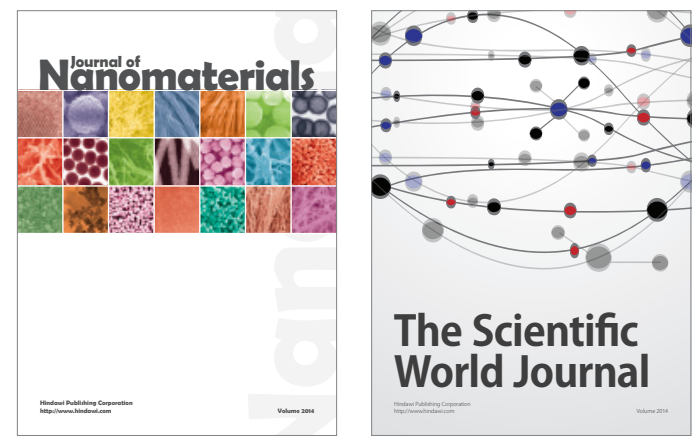

The Scientific World Journal
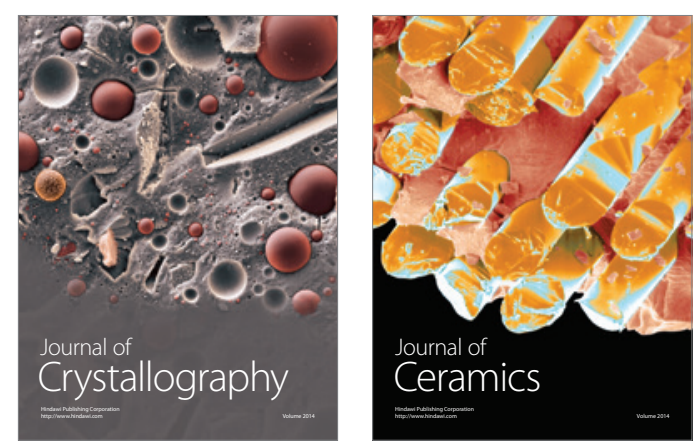
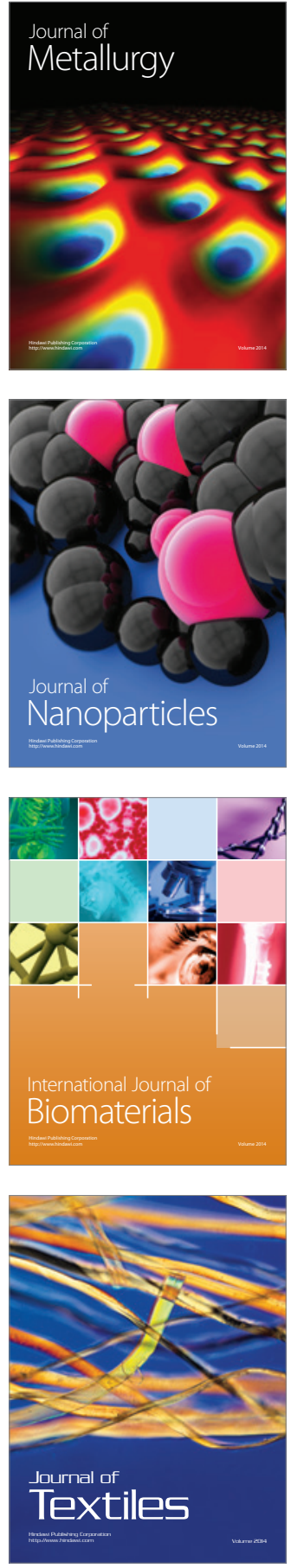